Portland State University

PDXScholar

8-7-1972

\title{
An investigation of between-ear tympanometry measures in normal-hearing young adults
}

\author{
Barry Lynn Kimmel \\ Portland State University
}

Follow this and additional works at: https://pdxscholar.library.pdx.edu/open_access_etds

Part of the Speech and Hearing Science Commons, and the Speech Pathology and Audiology Commons

Let us know how access to this document benefits you.

\section{Recommended Citation}

Kimmel, Barry Lynn, "An investigation of between-ear tympanometry measures in normal-hearing young adults" (1972). Dissertations and Theses. Paper 1615.

https://doi.org/10.15760/etd.1614

This Thesis is brought to you for free and open access. It has been accepted for inclusion in Dissertations and Theses by an authorized administrator of PDXScholar. Please contact us if we can make this document more accessible: pdxscholar@pdx.edu. 
AN ABSTRACT OF THE THESIS OF Larry Lynn Riminel for the Master of Science in Speech presented August 7, 1972.

Title: An Investigation of Between-Ear Tympanometry Measures in Norma1-Hearing Young Adults.

APPROVED BY MEMBERS OF THE THESIS COMMITTEE:

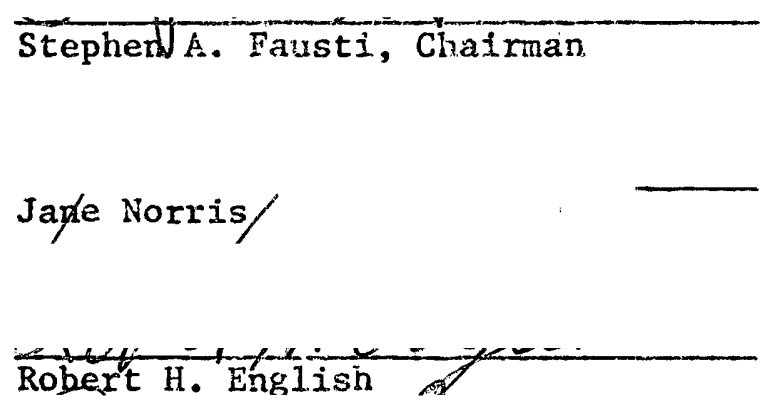

John o'Brien

In recent years, tynpanometry has been used to provide objective and definitive information regarding the status of middie ear conditions and functions. The present standard for tympanometric normalcy is based upon between-subject measures. This standard, however, does not allow precise differentiation between normal and pathological tympanometry curves. A within-subject comparison of right and left ear tympanometry curves of normal-hearing sub-jects could provide a narrow stanclard of tympanometric nomalcy which would be more useful in differentiating between pathologic 
and non-pathologic middle ear function. The within-subject relationship between tympanometry curves for right and left ears was Investigated by comparing the Individual right and jeft ear tympanometry curves at 220 and $660 \mathrm{~Hz}$ of 30 normal-hearing young adults. This was done to determine if a difference exists between within-subject right and left ear tympanometry curves. Three characteristics, curve peak amplitude, curve width, and pressure at curve peak, were measured and compared for each tympanometry curve. All tympanometry was conducted with a GrasonStadler Otoadmittance Meter (Mode1 1720) utslizing a combined mode of conductance and susceptance. All tympanometry curves were graphically recorded on a Hewlitt-Packard X-Y plotter (Model 7035B). Statistical analysis and graphic illustration showed that for practical purposes no significant clinical difference exists between within-subject right and left ear tympanomerry curves and that measurement variability is predominantly due to between-subject differences. The ranges of between-ear differences were much reduced in comparison to the computed ranges for between-subject measures. These findings would suggest that a definition of tympanometric normalcy should be based not only upon between-subject measures, but also upon between-ear comparisons. 
AN INVESTIGATION OF BETWEEN-EAR TYMPANOMETRY MEASURES

IN NORMAL-HEARING YOLNG ADULTS

by

BARRY LYNN KIMMEL

A thesis submitted in partial fulfillment of the requirements for the degree of

MASTER OF SCIENCE

in

SPEECH

Portland State University

1972 
TO THE OFFICE OF GRADUATE STUDIES:

The members of the Comittee approve the thesis of

Barry Lynn Kimmel presented August 7, 1972.

Stephen W. Fausti, Chairman

Jape Norris /

Robert H. English

Jopn O'Brien VT

APPROVED :

Robete Wo Vogelsang, Heqd, Departmeft of Speech

Dzvid T. Clark, Dean of Graduate Studies and Research

August 1I, 1972 
TABLE OF CONTENTS

PAGE

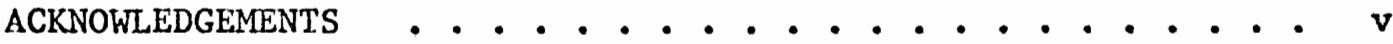

LIST OF TABLES ...................... vi

LIST OF FIGURES . . . . . . . . . . . . . . . . . viI

CHAPTER

I INTRODUCTION . . . . . . . . . . . . . . . 1

II REVIEW OF LITERATURE AND STATEMENT OF PROBLEM • • . 3

Review of Literature ........... 3

Statement of the Problem and the Purpose . . 16

III METHOD . . . . . . . . . . . . . . 18

Subjects ................ 18

Testing Environment . . . . . . . . 19

Administration of Tympanometry . . . . . 19

Additional Testing . . . . . . . . 23

Measurements .. . . . . . . . 23

IV RESULTS . . . . . . . . . . . . . . 25

Comparison of Right and Left Ears for Curve

Peak Amplitude, Curve Width, and Pressure

at Curve Peak . . . . . . . . . 25

Curve Peak Amplitude

Curve Width

Pressure at Curve Peak 
Regression Lines and Confidence Intervals

for Tympanometry Curve Measurements . . . .

Curve Peak Amplitude

Curve Width

Pressure at Curve Peak

Percentages of Measurement Variability Due To

Between-Subject Differences, Between-Ear

Differences, and Error of Measurement . . .

Curve Peak Amplitude

Curve Width

Pressure at Curve Peak

Relationships Between Individual RIght and

Left Ear Measurements . . . . . . . . 44

Curve Peak Amplitude

Curve Width

Pressure at Curve Peak

Results of Additional Testing . . . . . 52

Between-Subject Measurements . . . . . 53

V DISCUSSION AND RECOMMENDATIONS FOR FUTURE RESEARCH 56

VI SUMMARY AND CONCLUSIONS . . . . . . . . . 64

BIBLIOGRAPHY . . . . . . . . . . . . . . 68

APPENDIXES. . . . . . . . . . . . . . . . 70

A. SUBJECT INSTRUCTIONS ............ 71

B. INSTRUMENTATION . . . . . . . . . . 73

C. TYMPANOGRAM ................ 77

D. INDIVIDUAL TYMPANOMETRY CURVE MEASUREMENTS . . . 79

E. RESUlTS OF ADDITIONAL TESTING . . . . . . . 83 
ACKNOWLEDGEMENTS

The author would like to extend his grateful appreciation to Dr. Stephen A. Fausti who served as Chairman of his Thesis Committee and provided valuable support and guidance throughout this investigation. Sincere appreciation is expressed to each of the other members of the author's Thesis Committee, Mrs. Jane Norris, Dr. Robert H. English, and Dr. John O'Brien.

He is grateful to the Portland Veterans Administration for the use of its Audiology Clinic facilities in which this investigation was conducted.

A special note of thanks is extended to personnel in other Veterans Administration Services who participated in this study: Mr. Dean C. Altman and his staff in the Medical Illustration Service for their assistance on graphic illustrations; and Drs. John L. Traynor and Robert L. Moesinger in the Eye, Ear, Nose, and Throat Clinic for their participation in the otologic screening of subjects.

Further appreciation is extended to Dr. Quinten D. Clarkson of the School of Social Work for his generous assistance and guidance in the statistical treatment of data.

Finally, the author would like to thank P. L. Chapman for her excelient assistance in the preparation and typing of this thesis. 
J.T.ST OF TA.SLES

TABLE

PAGE

I Correlation (Pearson I) Between Right and Left

Ear Measurements of Curve Peak Amplitude . . . 26

II Correlation (Pearson $\underline{r}$ ) Between Right and Left

Ear Measurements of Curve Width . . . . . 27

III Correlation (Pearson $\underline{r}$ ) Between Right and Left

Ear Measurements of Pressure at Curve Peak . . 29

IV Percentages of Variation In Measurements of Curve

Peak Amp1itude Due to Differences Between

Right and Left Ears, Differences Between

Subjects, and Error of Measurement . . . . 39

$\mathrm{V}$ Percentages of Variation in Measurements of Curve

Width Due to Differences Between Right and

Left Ears, Differences Between Subjects,

and Error of Measurement .......... 41

VI Percentages of Variation in Measurements of Pressure

at Curve Peak Due to Differences Between Right

and Left Ears, Differences Between Subjects,

and Error of Measurement . . . . . . . 43

VII Between-Subject Ranges, Means, and Standard

Deviations for Measurements of Curve Peak

Amplitude, Curve Width, and Pressure at Curve

Peak at 220 and $660 \mathrm{~Hz}$.......... 54 


\section{LIST OF FIGURES}

FIGURE

PAGE

1. Idealized tympanometry curves for a normal

middle ear and for a middle ear containing fluid ................. 9

2. Idealized tympanometry curves showing pressure

and compliance for five middle ear

conditions . . . . . . . . . . . . 1

3. Basic components of the Grason-Stadler Otoadmittance Meter (Model 1720)........... 20

4. Regression line and 95 percent confidence interval

for individual right and left ear measurements of curve peak amplitude at $220 \mathrm{~Hz}$. . . . . 31

5. Regression line and 95 percent confidence interval

for individual right and left ear measurements of curve peak amplitude at $660 \mathrm{~Hz}$. . . . . 32

6. Regression line and 95 percent confidence interval

for individual right and left ear measurements of curve width at $220 \mathrm{~Hz}$. . . . . . .

7. Regression line and 95 percent confidence interval

for individual right and left ear measurements of curve width at $660 \mathrm{~Hz}$......... 34

8. Regression line and 95 percent confidence interval

for individual right and left ear measurements of pressure at curve peak at $220 \mathrm{~Hz}$. . . . 36 
9. Regression line and 95 percent confidence interval

for individual right and left ear measure-

ments of pressure at curve peak at $660 \mathrm{~Hz}$. . 37

10. Relationships between right and left ears for measurements of curve peak amplitude at

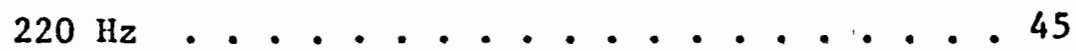

11. Relationships between right and left ears for measurements of curve peak amplitude at $660 \mathrm{~Hz}$...................46

12. Relationships between right and left ears for measurements of curve width at $220 \mathrm{~Hz}$. . . 48

13. Relationships between right and left ears for measurements of curve width at $660 \mathrm{~Hz} . . .449$

14. Relationships between right and left ears for measurements of pressure at curve peak at $220 \mathrm{~Hz}$. . . . . . . . . . 50

15. Relationships between right and left ears for measurements of pressure at curve peak at $660 \mathrm{~Hz}$.................... 51 


\section{CHAPTER I}

\section{INTRODUCTION}

Audiology can be generally defined as the study of hearing concerned with the diagnosis and remediation of auditory dysfunction (0'Neill and Oyer, 1966). The audiologist is primarily concerned with the identification and measurement of hearing disorders as they relate to the habilitation or rehabilitation of the hearing impaired. Determination of the type and degree of hearing loss is prerequisite to selecting appropriate prograins of habilitation, rehabilitation, or medical treatment in order to insure an optimal level of functioning for the hearing impaired individual.

Hearing loss is divided into two major categories, sensorineural and conductive. Sensorineural hearing loss results from cochlear or retrocochlear dysfunction and is considered to be a permanent type of hearing loss; however, through effective use of amplification and communication training, the handicapping effects of such a loss can ie substantially reduced.

A conductive hearing loss, on the other hand, is due to the insufficient transmission of sound through the middle ear. This usually occurs as a result of obstruction or alterations of the mechanical properties of the middle ear sound transmission system. Through the use of medication and improved surgical technique, 
physicians have successfully treated middle ear conditions responsible for a vast number of conductive hearing losses. The audiologist has played a vital role as a major contributor of diagnostic information critical to the design of medical treatment programs for hearing disorders.

Included within the audiologist's repertoire are many tests for assessment of the auditory system. Basic audiometry involves the recording of behaviorlal responses to pure tone stimuli. By varying the mode and manner of tonal stimulation, diagnostic information may be obtained to differentiate between conductive and sensorineural dysfunction and to identify the site of lesion. While most site-of-lesion testing has been directed toward the differential diagnosis of sensorineural pathologies, diagnostic tools for differentiating the various conductive or middle ear pathologies have been slow in development and less accurate. As a result, the audiologist has had to rely on less than ideal means to determine the status of the middle ear. The otological examination is greatly dependent upon the subjective impressions of the physician while the audiological evaluation depends on the subjective reporting and decisions by the patient. With the advent of instrumentation capable of recording changes in middle ear impedance, ${ }^{1}$ however, objective methods of differentiating between middle ear pathologies have evolved.

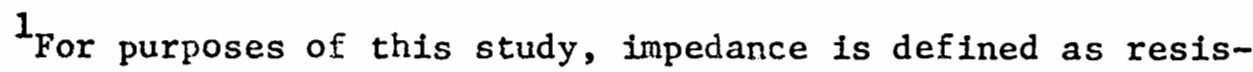
tivity to motion determining the vibrating efficiency of the midale ear system. 


\section{REVIEW OF LTTERATURE AND \\ STATEMENT OF PROBLEM}

\section{REVIEW OF LITERATURE}

In recent years, impedance measurements have been used to provide more objective and definitive information regarding the status of middle ear conditions and functions (Liden, Peterson and Bjorkman, 1970 a and b; Lilly, 1970; Lamb, 1971; Jerger, 1970; Feldman, 1971 b; Alberti and Kristensen, 1970; Klockoff, 1971; Nilges, Northern, and Burke, 1969; Liden, Peterson and Harford, 1970; Zwislocki and Feldman, 1970; Brooks, 1968, 1969). How efficiently the midale ear transmits sound energy is dependent on its capability as a mechanical transducer for providing an acoustic impedance match between air and fluid filled structures of the cochlea (Feldman, 1971 a). Under normal conditions the air pressure in the tympanic cavity and the ear canal are equal. Alterations in middle ear volume and pressure, as well as in its various fibrous and ligamentous connections affect sound vibration transmitted through the middle ear system. Conditions which interfere with the normal function of any portion of the system ultimately alter the mobility and impedance of the tympanic membrane through its direct or indirect attachment to the entire system. 
When sound strikes an object, a combination of three things occurs. The sound is: (a) reflected; (b) absorbed; and (c) transduced, depending upon the interplay between the various characteristics of the object and the sound itself. Specifically, the resistance, ${ }^{2}$ reactance, ${ }^{3}$ and compliance ${ }^{4}$ of the object will determine how the sound will be affected. The tympanic membrane also operates acoustically according to these same principles. It is the effect the tympanic membrane has upon an incident sound wave that underlies the operation of impedance measuring instrumentation. Impedance measurements rely upon calculating the difference in SPL between a known incident sound wave and that portion which is reflected from the tympanic membrane. This difference is usually computed in arbitrary units or equivalent units of cubic centimeters, ohms, or millimhos (reciprocal of milliohms), depending apon the impedarce measuring system being used.

2

For purposes of this study, resistance is defined as an element of friction which tends to impede the passage of sound energy through the middle ear system.

${ }^{3}$ For purposes of this study, reactance may either be defined as elements of mass (positive reactance) or stiffness (negative reactance), determining the degree to which sound energy is allowed to pass through the middle ear system.

${ }^{4}$ For purposes of this study, compliance is defined as mobility of the middle ear system and is inversely related to stiffness. Stiffness is mainly due to the ligaments of the middle ear, the tympanic membrane, and the volume of air enclosed within the middle ear space. 
The effects that elements of impedance have on the middle ear system for different frequencies were discussed by Feldman (1971). He noted that masses and resistances have little influence on the normal midale ear system in the low frequencies up to $500 \mathrm{~Hz}$ and the impedance is primarily an effect of the compliance or stiffness of the system. Above $500 \mathrm{~Hz}$, however, resistances can be expected to exert more influence on the middle ear system, and at the resonsance point of the ear, approximately 1000-1500 $\mathrm{Hz}$, the system becomes mass controlled. When the middle ear system becomes mass controlled, accurate measurements of compliance or resistance cannot be obtained.

According to Terkildsen and Nielsen (1.960), the first systematic study of acoustic impedance of the human ear was made by Troger in 1934. Schuster invented an acoustic impedance bridge, instrumentation which was eventually modified by Metz (1946) and used to make impedance measurements in both normal and pathological ears. When utilizing the Metz equipment, however, wide variations in the impedance values were observed. Consequently, during the late $1940^{\prime} \mathrm{s}$ and up through the early 1960's, it was felt by most investigators that standard otologic and audiologic procedures were of considerably more diagnostic value in determining middle ear pathulogy than were impedance measures.

Following Metz' (1946) work, other researchers (Terk1ldsen and Nielsen, 1960; Zwislock1, 1957, 1961, 1963; Moller, 1960;

Feldman, 1964) continued the work on impedance measurement. of 
the several methods available for the measurement of middle ear impedance, two have been applied clinically. The first of these is the mechanical acoustic bridge advanced by Metz (1946) and modified by Zwislocki (1961) for use on a broad clinical scale. The Zwislocki Acoustic Bridge allows compensation for variations in ear canal volume between the ear probe tip of the instrument and the tympanic membrane. Such compensation essentially eliminates errors in middle ear impedance measurement which might occur due to variations in ear canal volume. It also provides a stable matching impedance control over both resistance and reactance. The instrument obtains measures of resistance and reactance at the face of the tympanic membrane, thus providing absolute impedance $^{5}$ values. It also can be readily used for relative impedance 6 measurements to detect changes of impedance induced by contraction of one or both middle ear muscles.

A second clinical method of impedance measurement uses a modification of an electroacoustic impedance balancing system advanced originally by Terkildsen and Nielsen (1960). Such a system, the Madsen Acoustic Impedance Meter, has been used extensively in clinfal and research settings over the past several

5 For the purposes of this study, absolute impedance is defined as a measurement of middle ear inpedance determined by comparing impedance of the artificially stiffened and maximally compliant tympanic membrane.

${ }^{6}$ For purposes of this study, relative impedance is defined as any change in middle ear impedance produced when either of the middle ear muscles contracts. 
years (Li11y, 1970; Jerger, 1970; Alberti and Kristensen, 1970; Nilges, Northern and Burke, 1969; Brooks, 1968, 1969). Another commercially available electroacoustic impedance measuring system, the Grason-Stadler Otoadmittance Meter, has been recently developed. Both of these instruments, Madsen and Grason-Stadler, also permit absolute, as well as relative impedance measurements. In principle, the Grason-Stadler Otoadmittance Meter is similar to the Zwislocki Acoustic Bridge in that 1 t is designed to eliminate possible errors due to changes in ear canal volume so that impedance measurements are almost entirely associated with conditions existing at the plane of the tympanic membrane. By contrast, the Madsen Acoustic Impedance Meter lumps the conditions existing in the ear canal with the mixed conditions at the plane of the tympanic membrane, a method of measurement which does not compensate for the possible effects of the ear canal on impedance measurement or differentiate between the components of resistance and compliance contributing to middle ear impedance. While impedance measurement can be accomplished at several different frequencies with the Zwislocki Acoustic Bridge, the GrasonStadler Otoadnittance Meter permits measurements at two different test tones $(220$ and $660 \mathrm{~Hz}$ ) in contrast to the single test tone (220 Hz) capability of the Madsen Acoustic Impedance Meter. 
Basically, the Grason-Stadler Otoadmittance Meter is designed to measure admittance. 7 Sound pressure and sound flow of the probe tone are electronically controlled so that pressure and flow can exist in either a 0 degree phase relationship or a phase relationship where flow precedes pressure by 90 degrees. The 0 degree phase condition obtains a component of admittance known as conductance ${ }^{8}$ which is characterized by friction. When sound flow precedes sound pressure by 90 degrees, a component of admittance referred to as susceptance ${ }^{9}$ is obtained which is characterized by compliance or stiffness. Electronic switching also allows conductance and susceptance to be combined, a condition when sound flow is neither exactly in phase nor 90 degrees out-of-phase with pressure. This latter condition closely approximates the method of measurement incorporated in the Madsen Acoustic Inpedance Meter.

Electroacoustic impedance measuring systems introduce another concept, that of tynpanometry. Tympanometry may be generally defined as a measurement of tympanic membrane compliance, or mobility, during artiflcially induced air pressure changes in

7 The manufacturers of the Grason-Stadler Otoadmittance Meter refer to admittance as the reciprocal of impedance.

${ }^{8}$ The manufacturers of the Grason-Stadler Otoadmittance Meter refer to conductance as the reciprocal of resistance.

9 The manufacturers of the Grason-stadler Otoadmittance Meter refer to susceptance as the reciprocal of reactance. 
the ear canal (Jerger, 1970; Liden, Peterson and Bjorkman, 1970 a; Lamb, 1971). It involves three essential measures: (1) the compliance of the tympanic membrane when air pressure conditions In the ear canal are optimum; (2) the degree of compliance change with only slight deviation from the optimal ear canal air pressure; (3) the amount of ear canal air pressure necessary to bring the tympanic membrane to its most compliant position (Lamb, 1971). The basic datum of tympanometry is a graphic recording of the pressure-compliance function relating compliance changes to air pressure variations.

Several characteristics which may be observed from tympanometric pressure-compliance function curves are shown in Figure 1 and depicted as follows: (1) effective middle ear compliance indicated by the height of the curves; (2) shape of the curves near their peaks, the gradient; and (3) air pressure within the middle earcavity, shown by the point on the pressure continuum at which maximum compliance is attained (Liden, Peterson and Bjorkman, 1970 a; Lamb, 1971; Brooks, 1969).

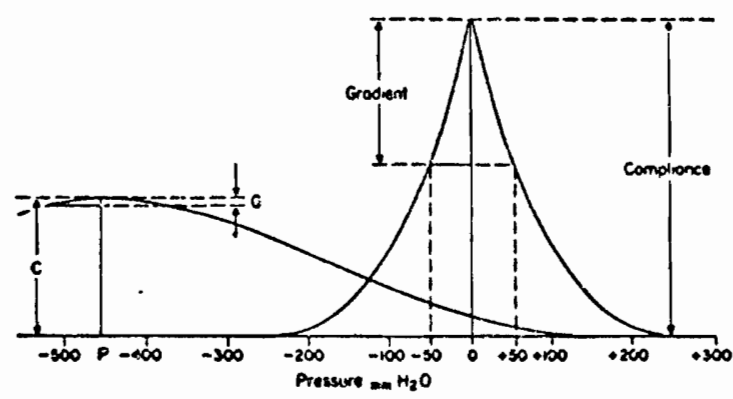

Figure 1. Idealized tympanometry curves for a normal middle ear and for a middle ear containing fluid (P). The degree of compliance and gradient is shown for each curve. (Brooks, 1969.) 
In comparing tympanograms obtained at three different probe frequencies $(220,625$ and $800 \mathrm{~Hz}$ ) for their group of normalhearing subjects, Liden, Peterson and Bjorkman (1970 b) observed statistically non-significant differences anong the three frequencies to be in the shape of the tympanometry curve under positive air pressure and in the depth and position of the curve peak. Jerger (1970) and Lamb (1971) described basic types of pressure-compliance functions. One type is characterized by a relatively sharp point of maximum compliance at or near $0 \mathrm{~mm} \mathrm{H} \mathrm{H}_{2} \mathrm{O}$ of air pressure. A relatively deep compliance function of this type is indicative of ossicular chain discontinuity, while a shallow rise in maximum compliance would be diagnostic of otosclerosis. A normal compliance maximum ranges between these two extremes. A second type shows little or no point of maximum compliance with compliance remaining essentially unchanged over a wide range of pressure variation. This second type usually indicates serous or adhesive otitis media. In a third type, the maximum is shifted to the left of $0 \mathrm{~mm} \mathrm{H} \mathrm{H}_{2} \mathrm{O}$ on the pressure continuum by negative pressure in the middle ear. A significant shift of $100 \mathrm{~mm}$ or more is commonly assoclated with Eustachian tube malfunction. These three basic types of tympanometry curves are illustrated in Figure 2. 


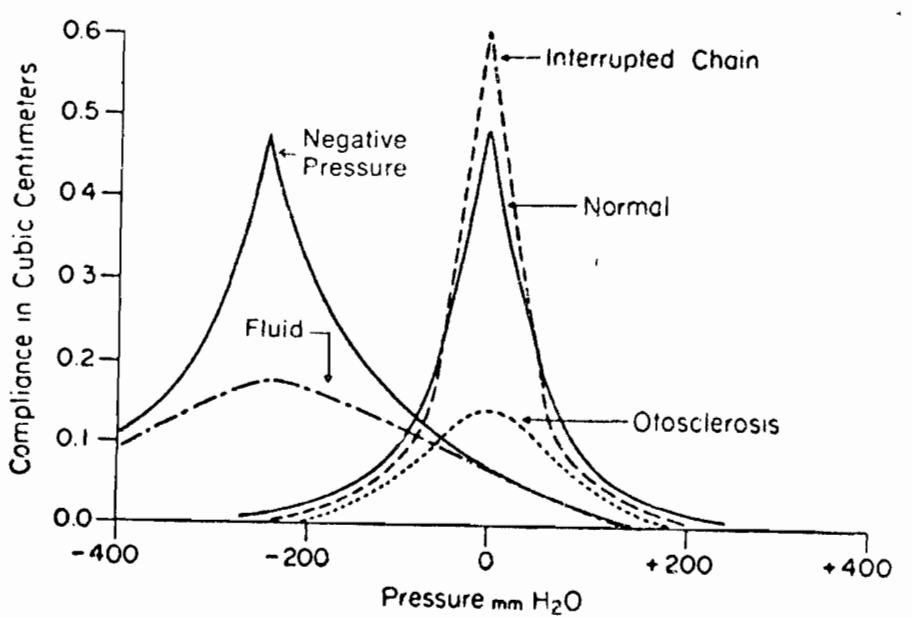

Figure 2. Idealized tympanometry curves showing pressure and compliance for five middle ear conditions. (Lamb, 1971.)

Not only has tympanometry been shown to be a practical, expedient clinical test of tympanic membrane and specific middle ear conditions (Liden, Peterson and Bjorkman, 1970 a and b; Alberti and Kristensen, 1970; Jerger, 1970), but it also has the advantage of being an objective measure of these conditions in contrast to the subjectivity of standard otological and audiological evaluations of general middle ear function. Because tympanometry does not require the patient to be cooperative and respond voluntarily, it has been utilized in unique clinical situations. When hearing thresholds cannot be validly determined through conventional pure-tone audiometry, as the case may be with a yound child (Jerger, 1970; Alberti and Kristensen, 1970) or mentally retarded 
Individual (Lamb, 1971), tympanometry may be used to confirm the presence of conductive pathology. Tympanometry also is helpful in providing information about middle ear function when the hearing loss is of such magnitude that bone conduction thresholds cannot be measured within the limits of the audiometer (Jerger, 1970). Brooks (1968) advocated the use of tympanometry in school screening programs to detect children with middle ear disease who otherwise would have passed an audiometric screening test. Since its recent inception, tympanometry has been recognized as an objective measure of middle ear function. Narrowly defined, tympanometric standards must be established before its maximum potential, as a diagnostic tool, can be realized.

Several researchers have described idealized "normal" tympanometry curves, but have falled to establish useful clinical norms for distinguishing between normal and pathological middle ears when comparing within-subject right and left ear tympanometry curves (Jerger, 1970; Liden, Peterson and Bjorkman, 1970 a; Lamb, 1971). Liden, Peterson and Bjorkman obtained data on four tympanometric curve characteristics for their group of otologically and audiologically normal hearing subjects. AccordIng to these investigators, the data showed little spread around the obtained means for these measured characteristics, indicating good between-subject stability for normal tympanometry curves. The standard deviations from the means, however, showed a range 
of variation which could be rather inconclusive diagnostically when comparing within-subject right and left ear tympanometry curves that are significantly different but still within the range of tympanometric normalcy based on between-subject measures. The task of differentiating between a normal and pathological middle ear becomes more difficult when tympanometry curves indicative of ossicular chain discontinuity and otosclerosis are of the same type as normal tympanometry curves; the only major feature distinguishing these three curves from one another being relatively different points of maximum compliance along a compliance continuum (Lamb, 1971; Jerger, 1970). Further, Liden (1970 b) showed that there was no statistically significant difference between the means for tympanometry curve measurements for his normal and otosclerotic groups.

A number of variables may account for the observed range of between-subject varlation in normal tympanometry curves. Lilly (1970) compared two tympanometry curves measured on the same ear of one of his normal-hearing subjects. Using a Madsen Acoustic Impedance Meter, the first measurement was accompifished wth the Madsen ear canal probe tip inserted in a conventional manner while the second measurement was recorded with the probe tip intentionally pushed deeper into the ear canal reducing the volume of air within the ear canal. By comparing the two curves, Lilly noted that a reduction of the volume of air within the ear 
canal moved the tympanometry curve upward and also changed its shape. This observation seemed to suggest that the shape of a "normal tympanometry curve" and its relative position on the form is dependent upon several. factors which are: (1) the crosssectional area of the eardrum and the external auditory meatus; (2) the volume of air between the tip of the probe and the ear drum; and (3) the acoustic conditions that exist at the surface of the eardrum. These variables are highly individualized and, as such, provide a possible explanation for the wide variation in between-subject tympanometric normalcy.

By measuring both the right and left ear canal volumes of his subjects, Feldman (1967) learned that although there was a considerable range of individual differences, a strong correlation existed between the within-subject right and left ear canal volumes. His data implied that the measured ear canal volume for one ear can be used for the second ear with a fair degree of confidence and that the difference between volumes would not be expected to exceed 0.1 cubic centimeters. This is in contrast to Feldman's anticipated ear canal volume range for 80 percent of an adult population which showed between-subject ear canal volume differences to vary as much as 0.4 cubic centimeters. It may be Inferred from Feldman's observations that within-subject anatomical symmetry allows some degree of control over variables which affect tympanometry curves, $1 . e .$, ear canal volume, crosssectional area of the eardrum and external auditory meatus. 
Another anatomical structure controling ear canal volume during tympanometry is the cartilaginous margin of the external auditory meatus which limits the insertion depth of the ear probe tip used with the electroacoustic impedance measuring systems (Lilly, 1970). While this cartilaginous margin would be expected to be anatomically similar for an individual.'s right and left ears, it could vary considerably between persons. Betweensubject anatomical variation in this margin, to the extent that it regulates ear canal volume during tympanometry, may then be partly responsible for the wide range of between-subject variation seen in tympanometry curves considered to be normal.

Because of within-subject anatomical symmetry, the previously mentioned anatomical variables are reduced when comparing an individual's right and left ears. Right and left ear tympanometry curves for an otologically and audiologically normal individual, therefore, would be expected to be in very close agreement in contrast to the range of variation observed for between-subject normal ear measurements. The present range of tympanometric normalcy based on between-subject measures permits within-subject right and left ear tympanometry curves to be significantly different and still be contained within normal limits. By obtaining strictly delimited within-subject $a_{\zeta}$ reement between right and left ear tympanometry curves, a range of within-subject normalcy may be defined which could be diagnostically more useful for differentiating between pathologic and non-pathologic ears than 
the present standard based upon between-subject measures. Such a within-subject definition of normalcy may provide a more efficient and reliable nethod of evaluating an individual's middle ear function even though his hearing is audiometrically normal. While between-subject variations in the "normal tympanometry curve" appear non-significant, these same variations in withinsubject measurements could be diagnostically indicative of existing middle ear pathology.

\section{STATEMENT OF THE PROBLEM AND THE PURPOSE}

Before one can realize the maximum potential of tympanometry as a diagnostic tool on a broad clinical basis, the "normal" tympanometry curve must be made more definitive for distinguishing between normal and pathological middle ears. Review of the literature has shown that no attempts have been made to establish a range of normalcy for within-subject tympanometry curves. A more narrowly defined within-subject range of normalcy derived from a comparison of right and left ear tympanometry curves could provide diagnostically useful information for differentiating between pathologic and non-pathologic middle ear function. The purpose of this study was to investigate the withinsubject relationship between tympanometry curves for right and left ears in a sample of normal-hearing subjects. The following 
question was investigated: Is there a difference between withinsubject right and left ear tympanometry curves? If a difference does not exist between within-subject right and left ear tympanometry curves a narrowly defined range of normalcy could be derived from these within-subject measurements which would allow precise differentiation between normal and pathological middle ears.

Such information should improve the diagnostic usefulness of tympanometry. 


\section{CHAPTER III}

METHOD

To compare the relationship between within-subject right and left ear tympanometry curves in a sample of normal-hearing subjects, the following methods and procedures were used.

\section{SUBJEC'TS}

Thirty normal-hearing young adults were selected to serve as subjects for this experiment. In order to control for possible effects of age or auditory pathologies, subjects were chosen according to the following criteria: (1) be $18-30$ years of age; (2) present a negative history of middle ear pathology, noise exposure or hereditary deafness; (3) have normal ears by otologic examination (otologic screening was conducted in the Ear, Nose, Throat Clinic, Veterans Administration Hospital); (4) have normal hearing as indicated by pure-tone sensitivity of $10 \mathrm{~dB}$ (ISO, 1964) or better for the frequencies of $250,500,1000$ and $2000 \mathrm{~Hz}$. Otologic and audiologic examinations were administered immediately prior to tympanometric evaluation.

of the thirty-six individuals who received otologic and audiologic examinations, six individuals did not qualify as subjects for this experiment. Three of these six individuals presented a positive history of middle ear pathology, one did not pass 
the otologic examination, one did not have normal pure-tone hearing sensitivity, and one did not have normal pure-tone hearing sensitivity or pass the otologic examinations. It should be noted that for two of the individuals presenting positive histories of middle ear pathology, tympanometry curves were obtained which were consistant with scarred tympanic membranes (Liden, Peterson, Bjorkman, 1970 b) although otologic examination did not provide such evidence.

\section{TESTING ENVIRONMENT}

Although tympanometry need not be administered in a special acoustically treated room, the use of a single-walled Industrial Acoustics Company (IAC) sound treated room (Model 404) located in the Veterans Administration Hospital Audiology Clinic, Portland, Oregon, allowed a more controlled environment for test purposes. This room provided a quiet atmosphere, relatively devoid of potential environmental distractions which might interfere with test administration.

III. ADMINISTRATION OF TYMPANOMETRY

A Grason-Stadler Otoadmittance Meter (Mode1 1720) was used to administer tympanometry. Figure 3 illustrates the basic components of this instrument. The Grason-Stadler Otoadmittance * Meter system utilizes an optional X-Y plotter (Hewlitt Packard, 


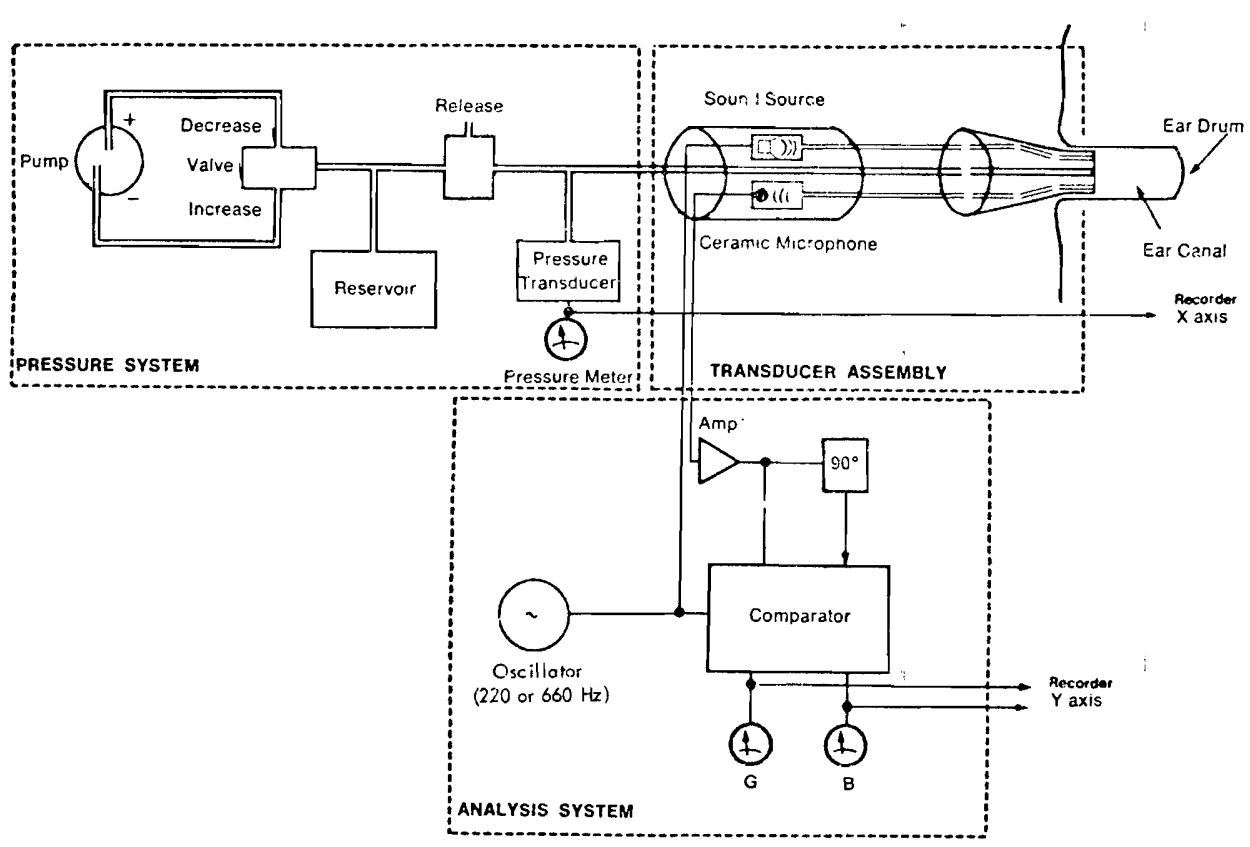

Figure 3. Basic components of the Grason-Stadler Otoadmittance Meter (Nodel 1720). (Grason-Stadler Company, 1971).

Model 7035B), which allowed a graphic recording of tympanometry curves (see Appendix B, Figure 1). An adjustable headband held the earpiece in position on the subject and an inflatable rubber cuff surrounding the ear probe tip was adaptable for all subjects (see Appendix B, Figure 2). The ear probe tip terminates in three capillary tubes that feed into the ear canal. One leads to a microphone and registers the sound pressure level, a second leads from a scund source generating the probe tone, and the third supplies a variable static air pressure that can be superimposed on the sound pressure for tympanometry. 
The Otoadmittance Meter system is fully automated and automatically adjusts the intensity of the test tone until a reference level of $85 \mathrm{~dB}$ SPL within the ear canal is achieved. Once a seal was achieved with the ear probe tip in the ear canal, tympanometry was conducted (Appendix B, Figure 3). All tympanometry testing was administered under a condition of decreasing air pressure from +200 to $-200 \mathrm{~mm} \mathrm{H}{ }_{2} \mathrm{O}$ over a period of 27 seconds for each test trial. Changes in admittance under a condition of continuously decreasing air pressure were automatically recorded on the $X-Y$ plotter.

Prior to tympanometric evaluation, each subject received a basic orientation to tympanometry as a method of evaluating middle ear function. For ease of test administration, subjects were seated in a comfortable chair facing away from the tympanometry instrumentation while being evaluated. Subjects were further instructed to refrain as much as possible from making head movements and swallowing during test administration since such motion may cause large irregularities in the tympanometry curve configuration. (See Appendix A for Subject Instructions.) Prior to each period of testing, the Otoadmittance Meter was checked for calibration with the test cavity supplied by the manufacturers. Before each test the ear probe tip was inspected and any cerumen occluding the capillary tubes of the probe tip was removed. Probe tones were monitored with a Hewlitt-Packard 
Frequency Counter (Model 5326A) and probe tone wave configurations were displayed on a Tektronix Dual-Beam Storage Oscilloscope (Model 5103N/D13). (See Appendix B, Figure 1.) Probe tones monitored at the level of the ear probe tip were found to be $218.5 \mathrm{~Hz}$ with the Otoadmittance Meter frequency selector switch set at $220 \mathrm{~Hz}$ and $659.2 \mathrm{~Hz}$ with the frequency selector switch set at $660 \mathrm{~Hz}$. Wave configurations for both probe tones displayed on the oscilloscope were sinusoidal.

Tympanometry curves were obtained for both right and left ears of each subject utilizing a combined mode of conductance and susceptance. Tympanometry was also conducted at both the 220 and $660 \mathrm{~Hz}$ probe tones in this experiment to determine the possible effects of probe tone frequency on tympanometric curve configurations (Appendix C).

For between-ear statistical comparisons, all tympanometry curves were labeled for right and left ears. To balance the effects of ordering, testing was alternated so that the right ear of each even-numbered subject and the left ear of each oddnumbered subject were the first ears tested for right and left ear measurements. Existing research did not indicate that artificially induced displacement of the tympanic membrane during tympanometry is physiologically fatiguing to the middle ear system. Therefore, ordering effects of the testing sequence for probe tones was not a concern, and tympanometry was first administered at $220 \mathrm{~Hz}$ and then at $660 \mathrm{~Hz}$ for all subjects. 


\section{ADDITIONAL TESTING}

Five subjects were retested within two weeks after initial evaluation for a reliability check of tympanometric measures. None of these subjects reported any conditions suggestive of middle ear pathology occuring between test-retest. Test administration for retest was the same as that used for initial testing.

\section{MEASUREMENTS}

Three curve characteristics, curve peak amplitude, curve width, and pressure at the curve peak, were measured for each tympanometry curve according to a method suggested by Liden (1970 a). Liden described curve peak amplitude as being the measured difference between the level of the lowest point on the tympanometry curve and the level of the curve peak. Liden calculated curve width by determining half the curve peak amplitude and projecting this point to the intersection with each half of the tympanometry curve, the width being the measured distance between these two points of intersection. Pressure at curve peak was characterized as the position of the curve peak relative to zero air pressure. Units of measurement for curve peak amplitude were millimhos and curve width and pressure at the curve peak were calculated in millimeters $\mathrm{H}_{2} \mathrm{O}$ of air pressure (Appendix C). A millimeter ruler was used to extrapolate pressure and millimhos measurements. 
Measurements in millimhos were accurate to the nearest .1 millimho and pressure measurements were judged to be accurate within \pm 2 millimeters $\mathrm{H}_{2} \mathrm{O}$. 


\title{
CHAPTER IV
}

\section{RESULTS}

\author{
I. COMPARISON OF RIGHT AND LEFT \\ EARS FOR CURVE PEAK AMPLITUDE, \\ CURVE WIDTH, AND PPESSURE \\ AT CURVE PEAK
}

The relationship between each subject's right and left ear tympanometry curve measurements was investigated using the Pearson Product-Moment Correlation (Bruning and Kintz, 1968). Correlations were computed for measurements of curve peak amplitude, curve width, and pressure at curve peak at both test frequencies under investigation in order to determine if a relationship existed between right and left ear tympanometry curves.

Curve Peak Amplitude

Right ear versus left ear correlations for measurements of curve peak amplitude are shown in Table I. Correlations of +.88 at $220 \mathrm{~Hz}$ and +.90 at $660 \mathrm{~Hz}$ were significant at the .05 and .01 confidence levels. (See Appendix D, Table I for measurements of curve peak amplitude for each subject.)

\section{Curve Width}

Table II displays the between-ear correlations for measurements of curve width at 220 and $660 \mathrm{~Hz}$. Correlations for measurements of curve width listed in Table II are +.88 at $220 \mathrm{~Hz}$ and 
TABLE I

CORRELATION (PEARSON r) * BETWEEN RIGHT AND LEFT EAR MEASUREMENTS OF CURVE PEAK AMPLITUDE

Curve Peak Amplitude for Right Ears vs

Curve Peak Amplitude for Left Ears

\begin{tabular}{|l|l|}
\hline $220 \mathrm{~Hz}$ & $660 \mathrm{~Hz}$ \\
\hline+.88 & +.90 \\
\hline
\end{tabular}

* $r$ necessary for significance; $\overline{a t} .05=.30$; at $.01=.42$. 
TABLE II

CORRELATION (PEARSON I) * BETWEEN RIGHT AND LEFT EAR MEASUREMENTS OF CURVE WIDTH

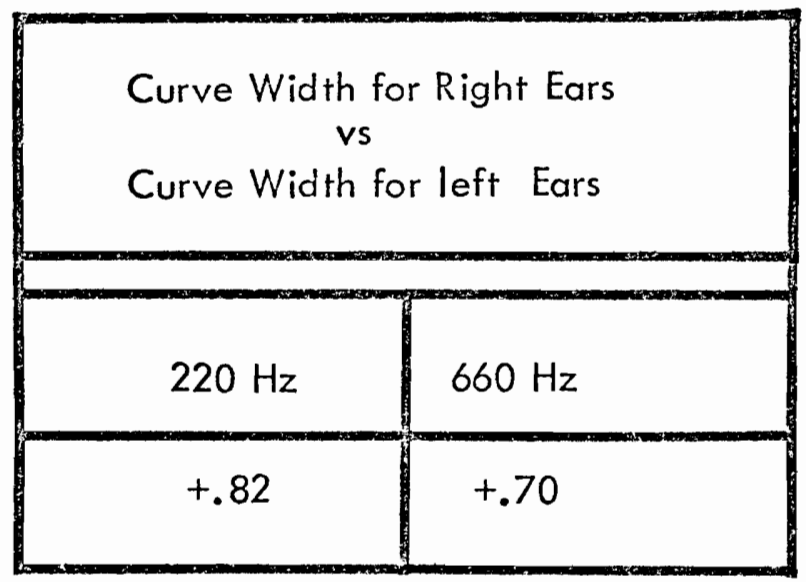

* $r$ s necessary for significance;

at $.05=.30$, at $.01=.42$. 
+.70 at $660 \mathrm{~Hz}$. Similar to correlations for measurements of curve peak amplitude, correlations for curve width are significant at the .05 and .01 confidence levels. (See Appendix D, Table II for measurements of curve width for each subject.)

\section{Pressure at Curve Peak}

Correlations for right ear versus left ear measurements of pressure at curve peak at 220 and $660 \mathrm{~Hz}$ are shown in Table III. As indicated by Table III, correlations for measurements of pressure at curve peak are +.39 at $220 \mathrm{~Hz}$ and +.24 at $660 \mathrm{~Hz}$. In contrast to the .05 and .01 levels of significance obtained for between-ear correlations for both measurements of curve peak amplitude and curve width, only the correlation for measurements of pressure at curve peak at $220 \mathrm{~Hz}$ was significant at the .05 leve1. (See Appendix D, Table III for measurements of pressure at curve peak for each subject.)

\section{REGRESSION LINES AND CONFIDENCE INTERVALS FOR TYMPANOMETRY \\ CURVE MEASURERENTS}

Tympanometry curve measurements for each subject were examined by computing regression line coefficients and constructing regression lines with confidence intervals for measurements of curve peak amplitude, curve width, and pressure at curve peak at 220 and $660 \mathrm{~Hz}$. Confidence intervals of 95 percent were computed in order to determine the degree of accuracy with which left ear 
TABLE III

CORRELATION (PEARSON r) * BETWEEN RIGHT AND LEFT EAR MEASUREMENTS OF PRESSURE AT CURVE PEAK

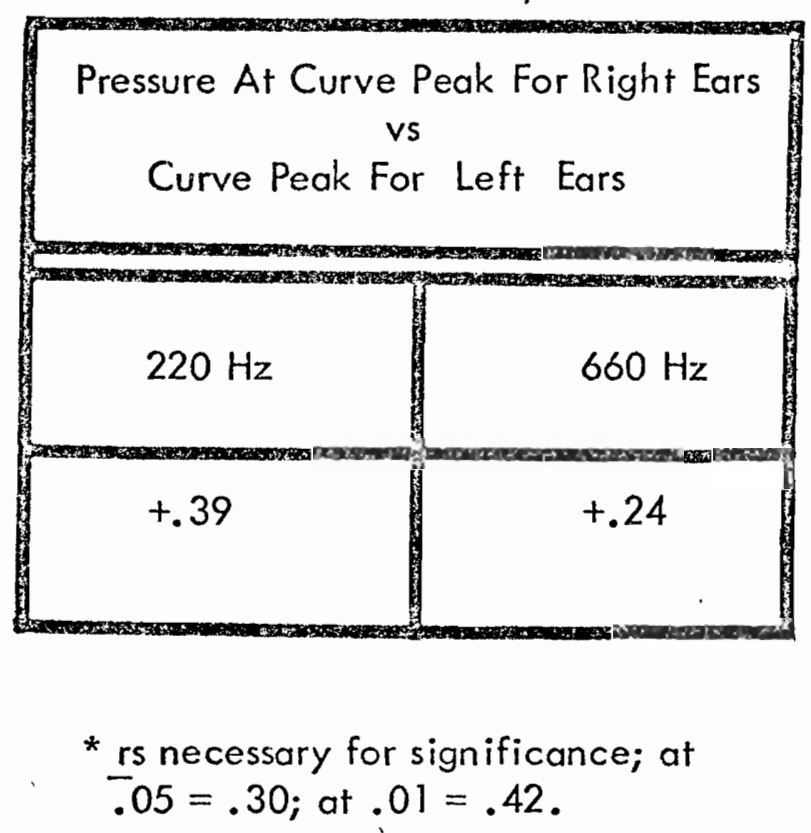


measurements may be predicted from right ear measurements according to linear regression.

\section{Curve Peak Amplitude}

Regression line coefficients for right and left ear measurements of curve peak amplitude were found to be .856 and .060 at $220 \mathrm{~Hz}$ and .860 and .198 at $660 \mathrm{~Hz}$. Regression lines with confidence intervals for measurements of curve peak amplitude at both test frequencies are shown in Figures 4 and 5 . The distributions of individual right and left ear measurements of curve peak amplitude depicted in Figures 4 and 5 show that all individual measurements are clustered rather closely around the regression lines. If lines were to be drawn parallel to and outside the confidence intervals at a distance of .07 mmhos for curve peak amplitude measurements at $220 \mathrm{~Hz}$ and .4 mmos at $660 \mathrm{~Hz}$, a1most the entire number of right and left ear measurements would be confined within a narrow set of boundaries.

\section{Curve Width}

Regression line coefficients of .756 and 22.367 at $220 \mathrm{~Hz}$ and .722 and 30.772 at $660 \mathrm{~Hz}$ were computed for right and left ear measurements of curve width. Figures 6 and 7 display the regression lines with confidence intervals for curve width measurements at both test frequencies. Similar to the distributions of right and left ear measurements of curve peak amplitude, the 


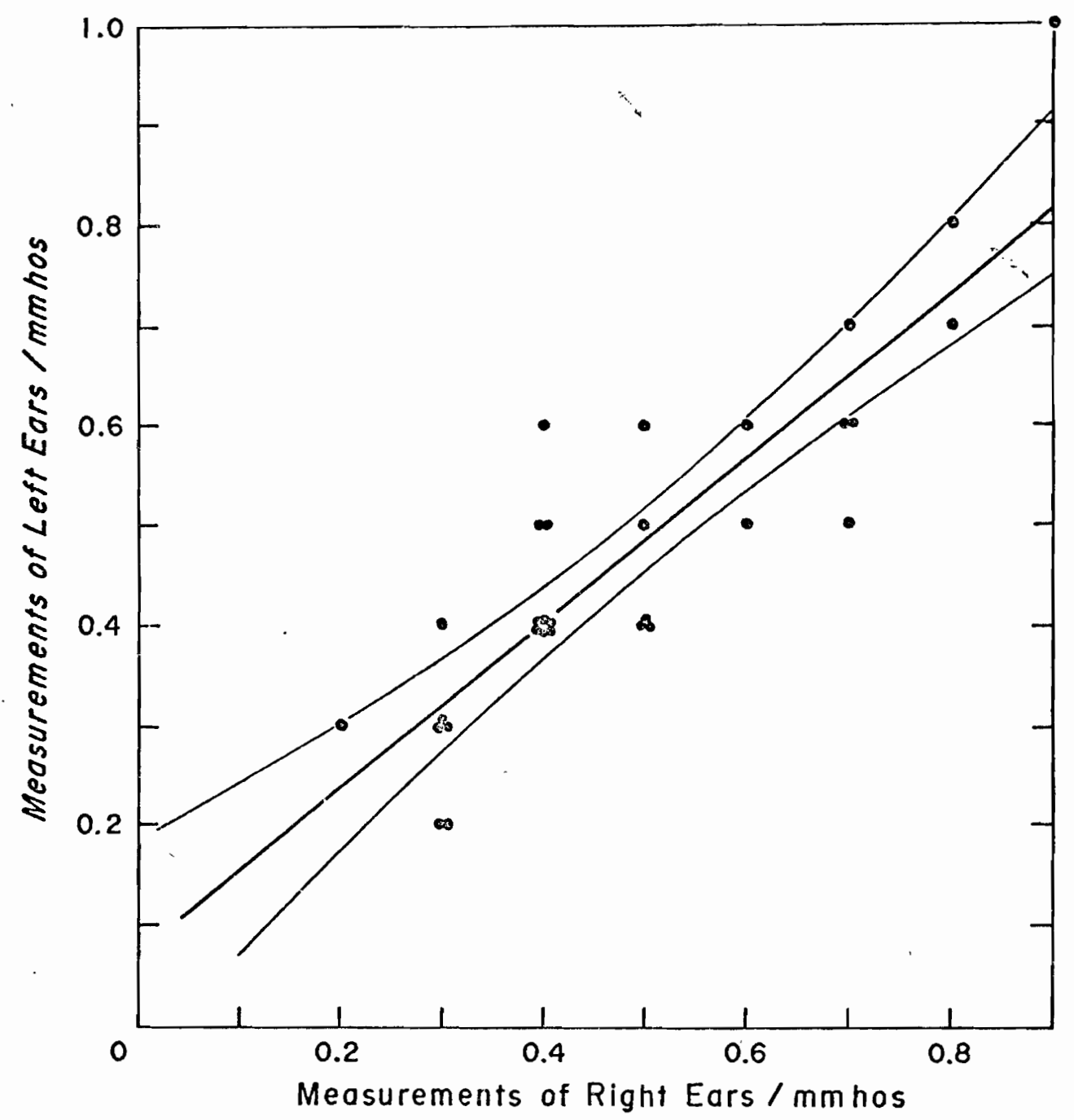

FIGURE 4. REGRESSION LINE AND 95\% CONFIDENCE IN TER VAL FOR INDIVIDUAL RIGHT AND LEFT EAR MEASUREMENTS OF CURVE PEAK AMPLITUDE AT $220 \mathrm{~Hz}$. 


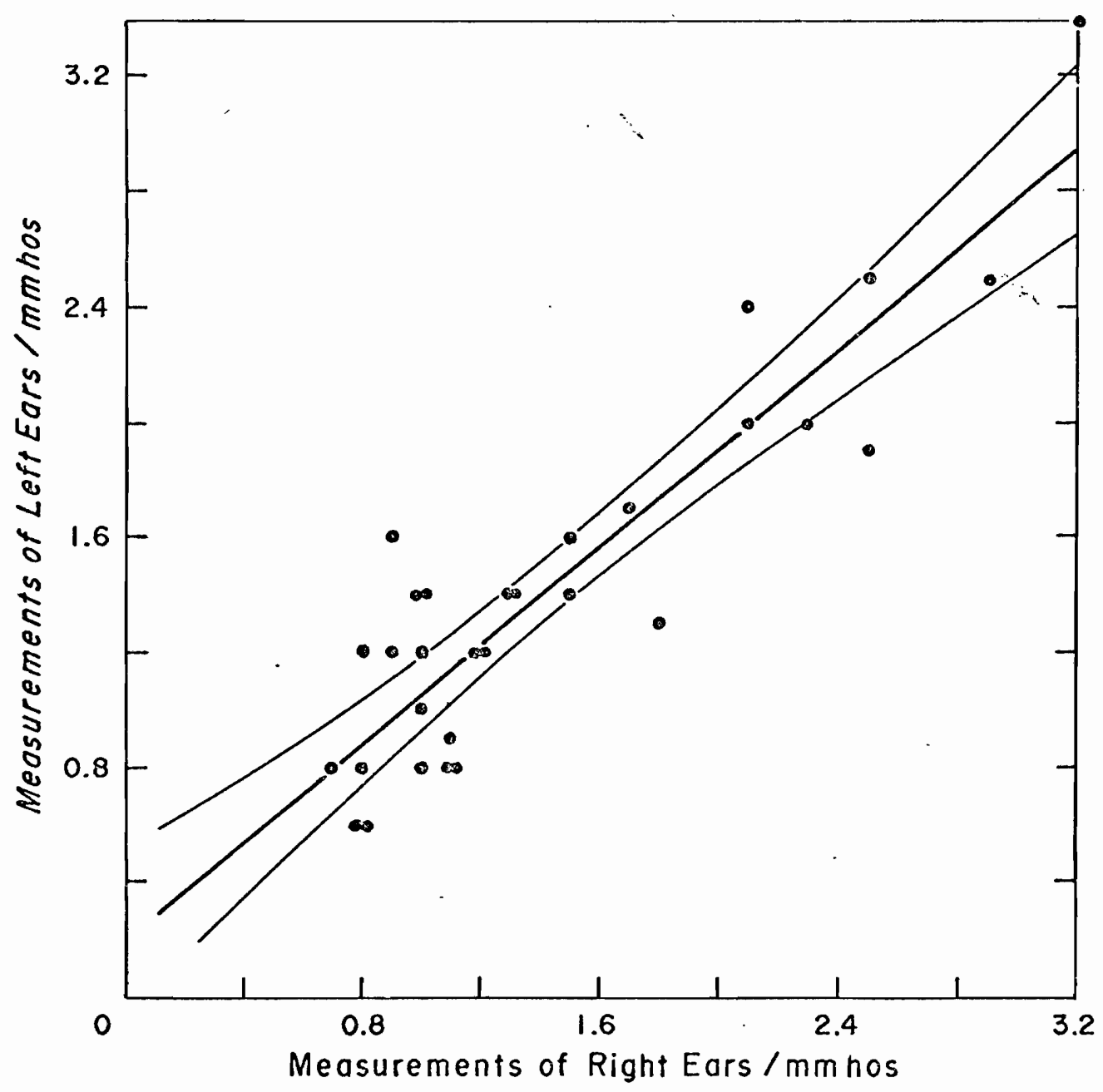

FIGURE 5. REGRESSION LINE AND 95\% CONFIDENCE INTERVAL FOR INDIVIDUAL RIGHT AND LEFT EAR MEASUREMENTS OF CURVE PEAK AMPLITUDE AT $660 \mathrm{~Hz}$. 


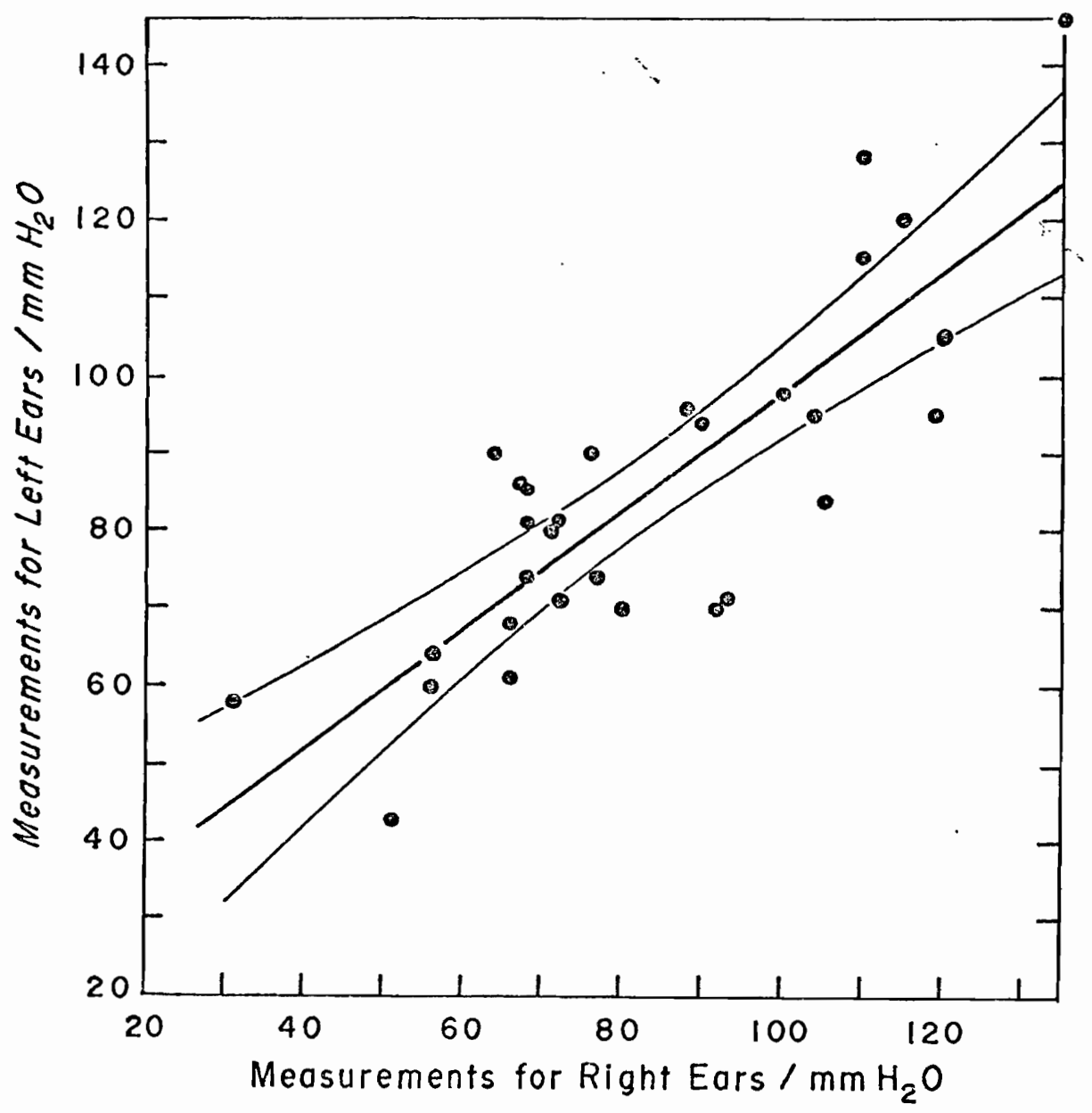

FIGURE 6. REGRESSION LINE AND 95\% CONFIDENCE INTERVAL FOR INDIVIDUAL RIGHT AND LEFT EAR MEASUREMEN TS OF CURVE WIDTH AT $220 \mathrm{~Hz}$. 


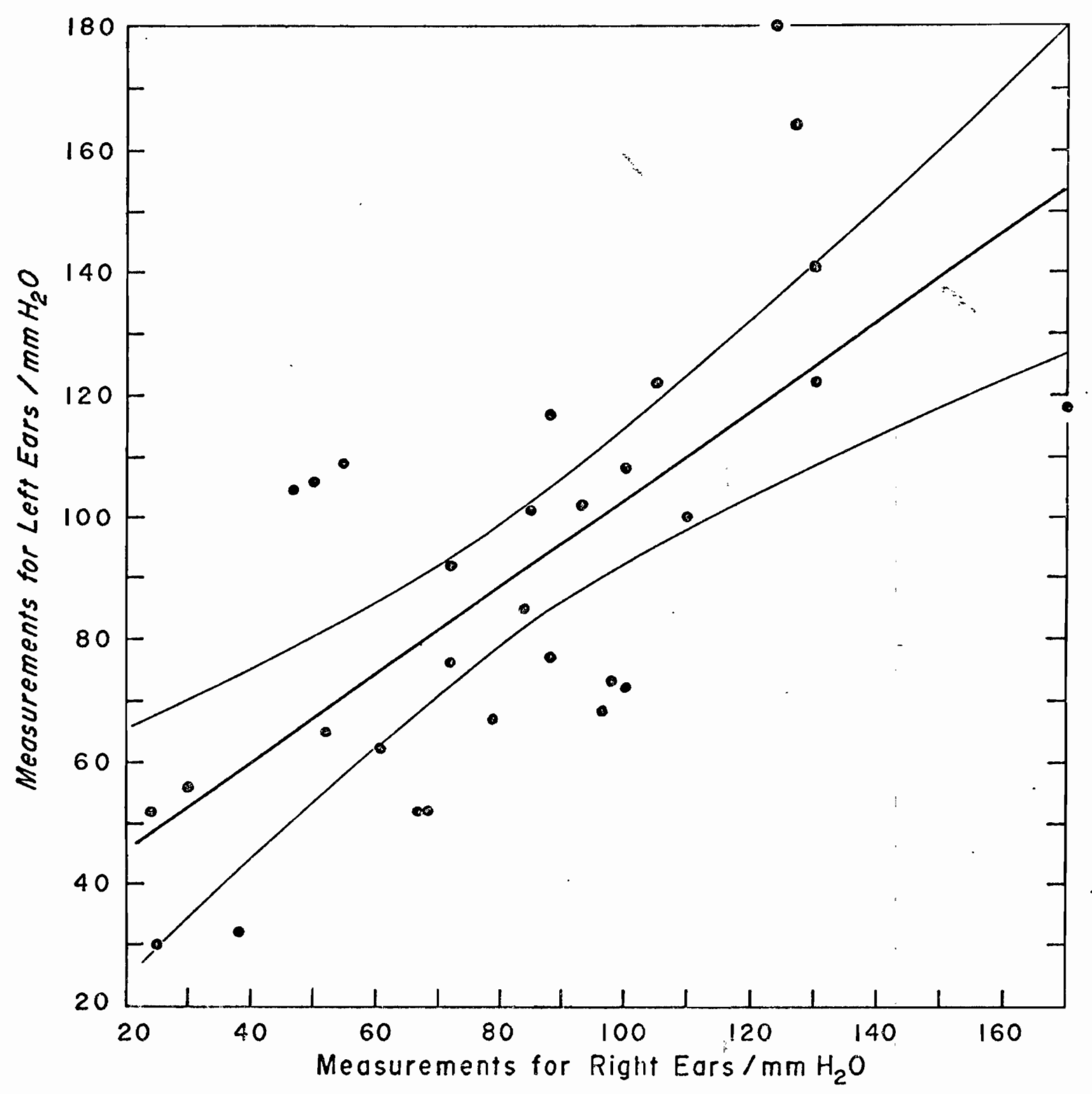

FIGURE 7. REGRESSION LINE AND 95\% CONFIDENCE INTERVAL FOR INDIVIDUAL RIGHT AND LEFT EAR MEASUREMENTS OF CURVE WIDTH AT $660 \mathrm{~Hz}$. 
distribution of curve width measurements at $220 \mathrm{~Hz}$ (Figure 6) is concentrated near the regression 1ine. The confidence interval in Figure 6 is also shown to deviate mininally from the regression line. Should this confidence interval be extended outward in both directions from the regression line an additional $11 \mathrm{~mm}$ $\mathrm{H}_{2} \mathrm{O}$, the right and left ear curve width measurements at $220 \mathrm{~Hz}$ for all but two subjects would be encompassed within this interval. Measurements of curve width at $660 \mathrm{~Hz}$ shown in Figure 7 are more widely distributed than the same measurements at $220 \mathrm{~Hz}$. The confidence interval in Figure 7 also deviates considerably more from the regression line than that observed for curve width measurements at $220 \mathrm{~Hz}$ indicating that a greater degree of variance exists for predicted left ear curve width measurements at $660 \mathrm{~Hz}$. The confidence interval for curve width measurements at $660 \mathrm{~Hz}$ would need to be expanded an additional $23 \mathrm{~mm} \mathrm{H}_{2} \mathrm{O}$ on both sides of the regression line to include 29 of the 30 subjects.

\section{Pressure at Curve Peak}

Regression lines for right and left ear measurements of pressure at curve peak were drawn according to regression line coefficients of .327 and 1.007 at $220 \mathrm{~Hz}$ and .229 and 3.979 at 660 Hz. Regression lines with confidence intervals for measurements of pressure at curve peak at both test frequencies are shown in Figures 8 and 9 . The most obvious descriptive feature of Figures 8 and 9 is the wide distribution of individual right and left ear 


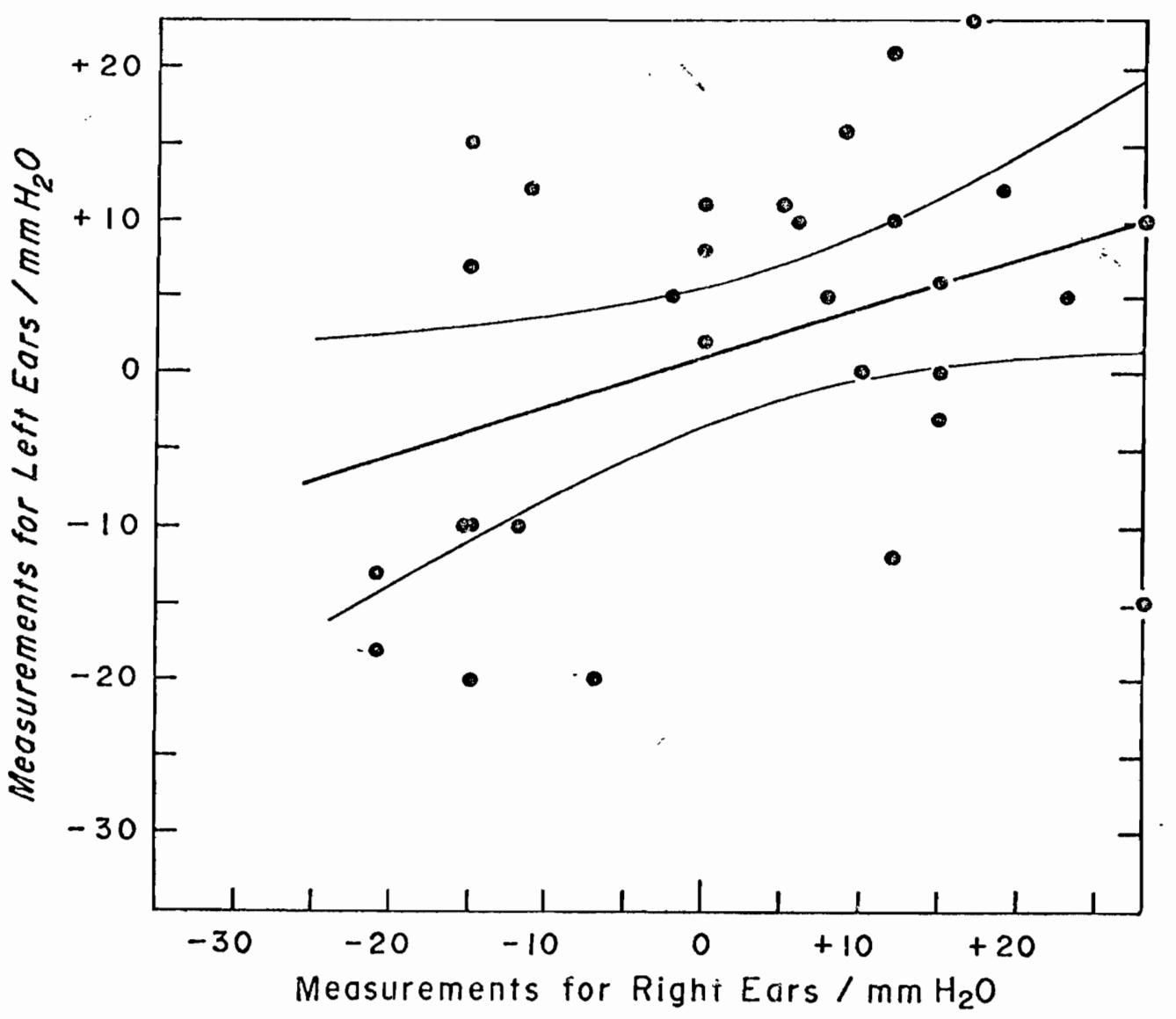

FIGURE 8. REGRESSION LINE AND 95\% CONFIDENCE INTERVAL FOR INDIVIDUAL RIGHT AND LEFT EAR MEASUREMENTS OF PRESSURE AT CURVE PEAK AT $220 \mathrm{~Hz}$. 


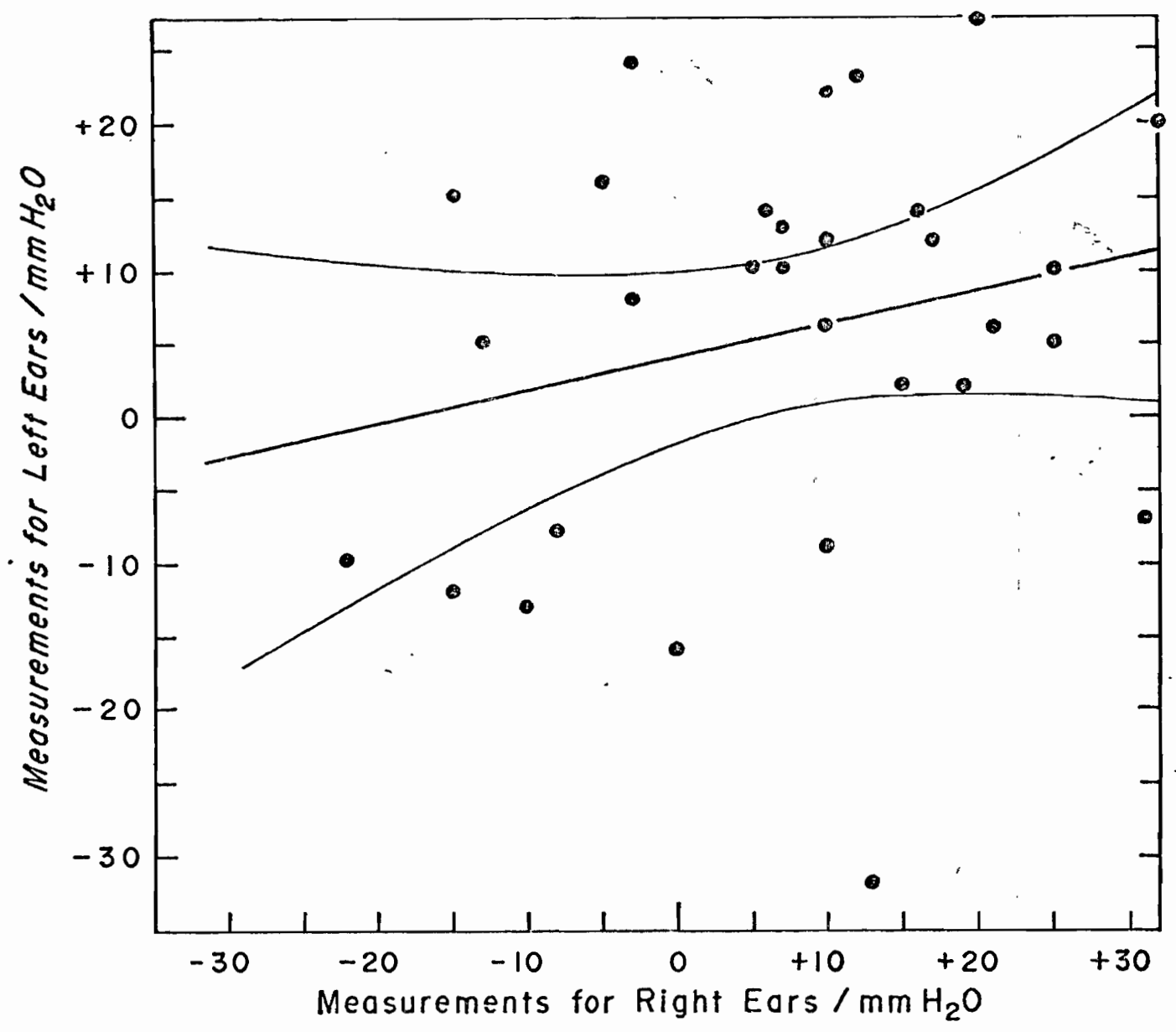

FIGURE 9. REGRESSION LINE AND 95\% CONFIDENCE INTERVAL FOR INDIVIDUAL RIGHT AND LEFT EAR MEASUREMENTS OF PRESSURE AT CURVE PEAK AT $660 \mathrm{~Hz}$. 
pressure at curve peak measurements through the entire range limits for pressure at curve peak measurements. Confidence intervals for these measurements allow a considerable amount of variance for predicted left ear pressure at curve peak measurements.

\section{PERCENTAGES OF MEASUREMENT VARIABILITY DUE TO BETWEEN-SUBJECT DIFFERENCES, BETWEEN-EAR DIFFERENCES, AND ERROR OF MEASUREMENT}

Analysis of variance was used to determine the amount that each of three sources of measurement variability (differences between subjects, differences between individual right and left ears, and error of measurement) contributed to the total measurement variability for tympanometry curve measurements at 220 and $660 \mathrm{~Hz}$. The sum of squares for each source of measurement variability was divided into the total sum of squares for all three sources of measurement variability. This was done to determine the percentage that each source of measurement variability contributed to the total measurement variability for the measures under investigation.

Curve Peak Amplitude

Table IV shows the percentage of total measurement variability due to between-subject differences, between-ear differences, and error of measurement for measurements of curve peak amplitude at 220 and $660 \mathrm{~Hz}$. As Indicated by Table IV, 100 percent of the measurement variability for measurements of curve peak 
PERCENTAGES OF VARIATION IN MEASUREMENTS OF CURVE PEAK AMPLITUDE DUE TO DIFFERENCES BETWEEN RIGHT AND LEFT EARS, DIFFERENCES BETWEEN SUBJECTS, AND ERROR OF MEASUREMENT




amplitude at $220 \mathrm{~Hz}$ is ascribed to between-subject differences with no measurement variability due to between-ear differences or error of measurement. At $660 \mathrm{~Hz}, 95.15$ percent of the total measurement variability for curve peak amplitude measurements was explained by between-subject differences with 4.85 percent of the total measurement variability being attributed to error of measurement. Table IV also Indicates that none of the total measurement variability at $660 \mathrm{~Hz}$ is attributed to between-ear differences.

\section{Curve Width}

The percentages of total measurement variability due to between-subject differences, between-ear differences, and error or measurement for measurements of curve width at 220 and $660 \mathrm{~Hz}$ are listed in Table $\mathrm{V}$. According to Table $\mathrm{V}$ between-subject differences account for 90.61 percent of the total measurement variability occurring at $220 \mathrm{~Hz}$ and 83.93 percent at $660 \mathrm{~Hz}$. of the remaining measurement variability for curve width measurements, variability was largely due to error of measurement which accounts for 9.21 percent of the total measurement variability at $220 \mathrm{~Hz}$ and 14.78 percent at $660 \mathrm{~Hz}$. Only a slight percentage of the total measurement variability, 0.18 percent at $220 \mathrm{~Hz}$ and 1.29 percent at $660 \mathrm{~Hz}$, was due to between-ear differences. 


\section{TABLE $V$}

PERCENTAGES OF VARIATION IN MEASUREMENTS OF CURVE WIDTH DUE TO DIFFERENCES BETWFEN RIGHT AND LEFT EARS, DIFFERENCES BETWEEN SUBJECTS AND ERROR OF MEASUREMENT

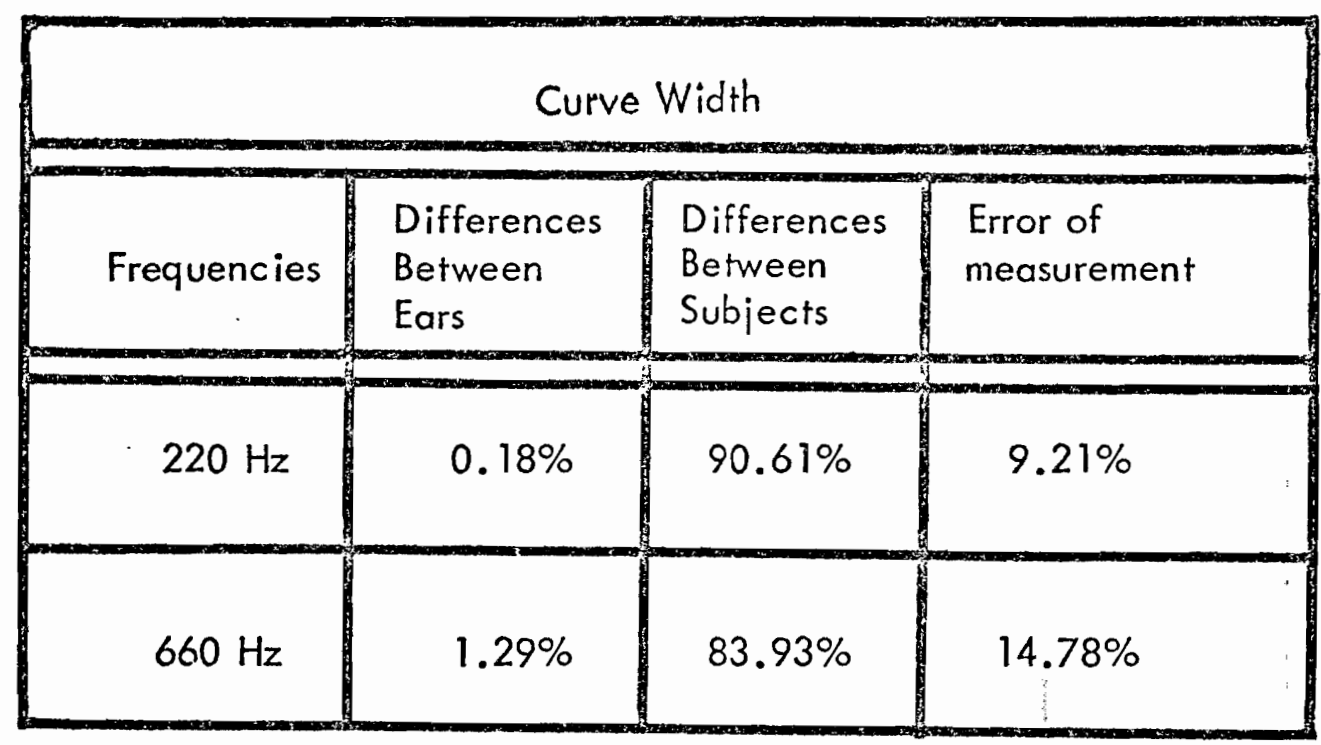




\section{Pressure at Curve Peak}

Table VI displays the percentages of total measurement variability due to between-subject differences, between-ear differences, and error of measurement for measurements of pressure at curve peak at 220 and $660 \mathrm{~Hz}$. As listed in Table VI, the percentages of total measurement variability attributed to between-subject differences are 66.72 percent at $220 \mathrm{~Hz}$ and 63.69 percent at 660 Hz. The second largest contributor to total measurement variability for measurements of pressure at curve peak was error of measurement, accounting for 33.16 percent of the total measurement variability at $220 \mathrm{~Hz}$ and 35.98 percent at $660 \mathrm{~Hz}$. As was the case with percentages of total measurement variability due to between-ear differences recorded for measurements of curve peak amplitude and curve width, the percentages of measurement variability due to between-ear differences for measurements of pressure at curve peak at both test frequencies were minimal, .12 percent at $220 \mathrm{~Hz}$ and 0.33 percent at $660 \mathrm{~Hz}$. In contrast to the percentages of total measurement variability due to between-subject differences and error or measurement recorded for curve peak amplitude and curve width measurements, the percentages of total measurement variability for pressure at curve peak measurements were substantially reduced for measurement variability due to between-subject differences and increased for measurement variability explained by error of measurement. 
PERCENTAGES OF VARIATION IN MEASUREMENT OF PRESSURE AT CURVE PEAK DUE TO DIFFERENCES BETWEEN RIGHT AND LEFT EARS, DIFFERENCES BETWEEN SUBJECTS, AND ERROR OF MEASUREMENT

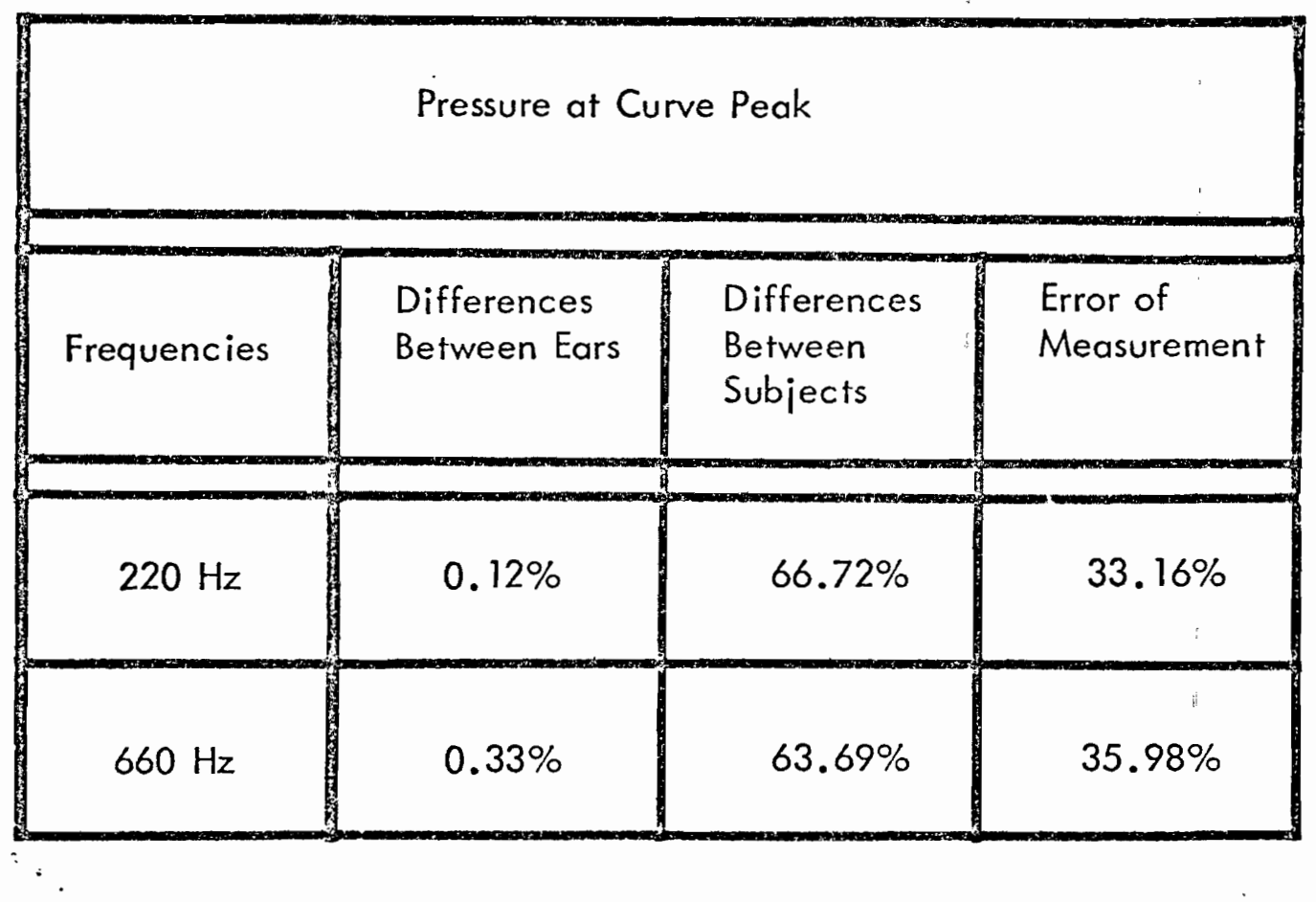




\section{RELATIONSHIPS BETWEEN INDIVIDUAL RIGH'T AND LEFT EAR MEASUREMENTS}

Differences between individual right and left ear measurements of curve peak amplitude, curve width, and pressure at curve peak at 220 and $660 \mathrm{~Hz}$ were computed. Using all right ear measurements as a baseline, the amount that left ear measurements differed from right ear measurements was calculated as a positive or negative deviation to demonstrate between-ear measurement relationships for each subject. The mean amount of between-ear measurement differences was computed for all subjects for the measurements under investigation.

\section{Curve Peak Amplitude}

Between-ear relationships for measurements of curve peak amplitude at 220 and $660 \mathrm{~Hz}$ (Figures 10 and 11) show a general tendency for the number of left ear measurements to be equally placed above and below the baseline for right ear measurements. These relationships also indicate that the magnitudes of differences between right and left ears for measurements of curve peak amplitude are fairly normally distributed with between-ear differences ranging from 0.0 to 0.2 mmhos at $220 \mathrm{~Hz}$ and from 0.0 to $0.7 \mathrm{mmhos}$ at $660 \mathrm{~Hz}$. No between-ear differences are demonstrated by 43 percent of the subjects represented in Figure 10 and 20 percent of the subjects in Figure 11. The mean differences between right and left ear measurements for all subjects were .063 at $220 \mathrm{~Hz}$ and .223 at $660 \mathrm{~Hz}$. 


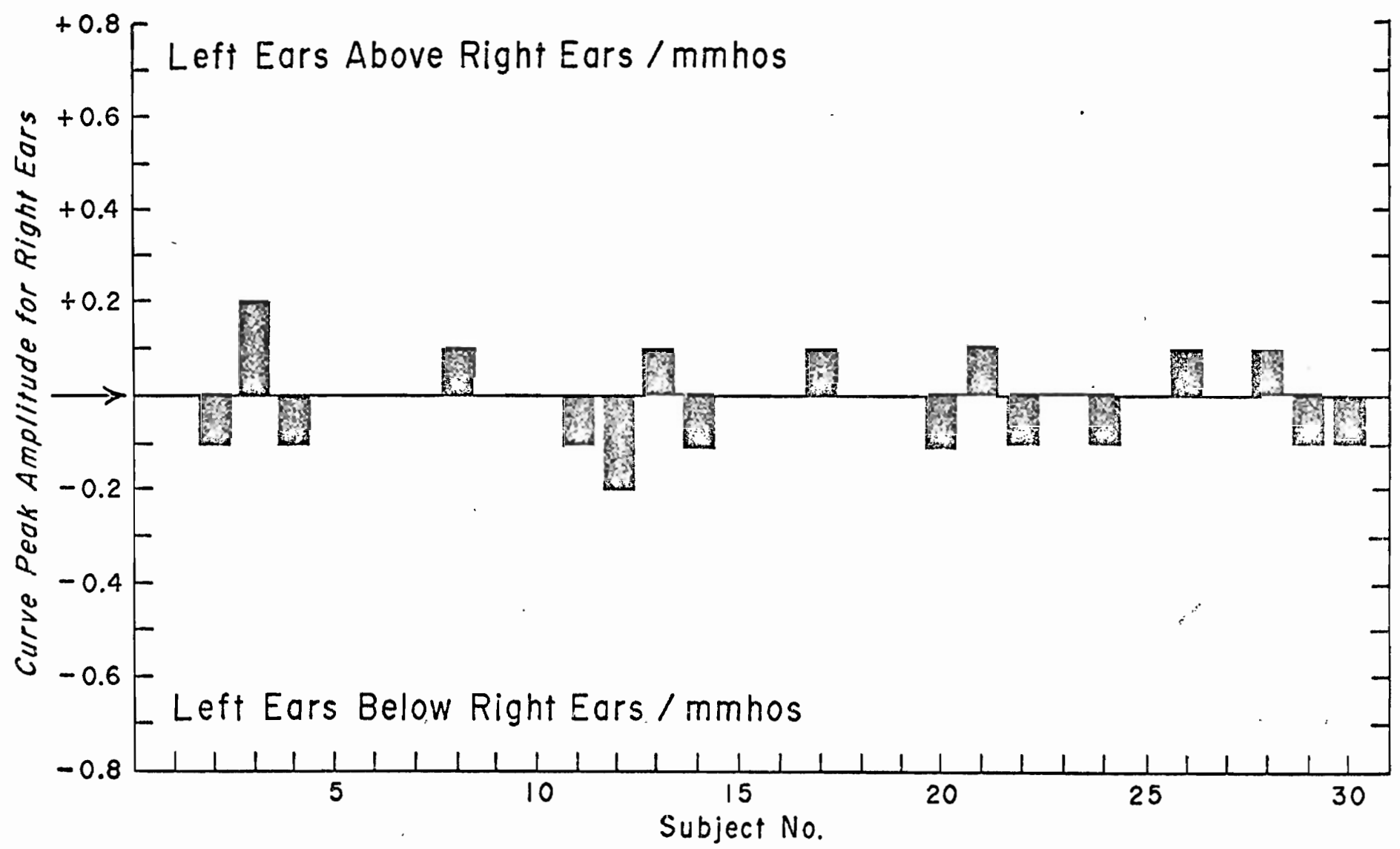

FIGURE 10. RELATIONSHIPS BETWEEN RIGHT AND LEFT EARS FOR MEASUREMENTS OF CURVE PEAK AMPLITUDE AT $220 \mathrm{~Hz}$. 


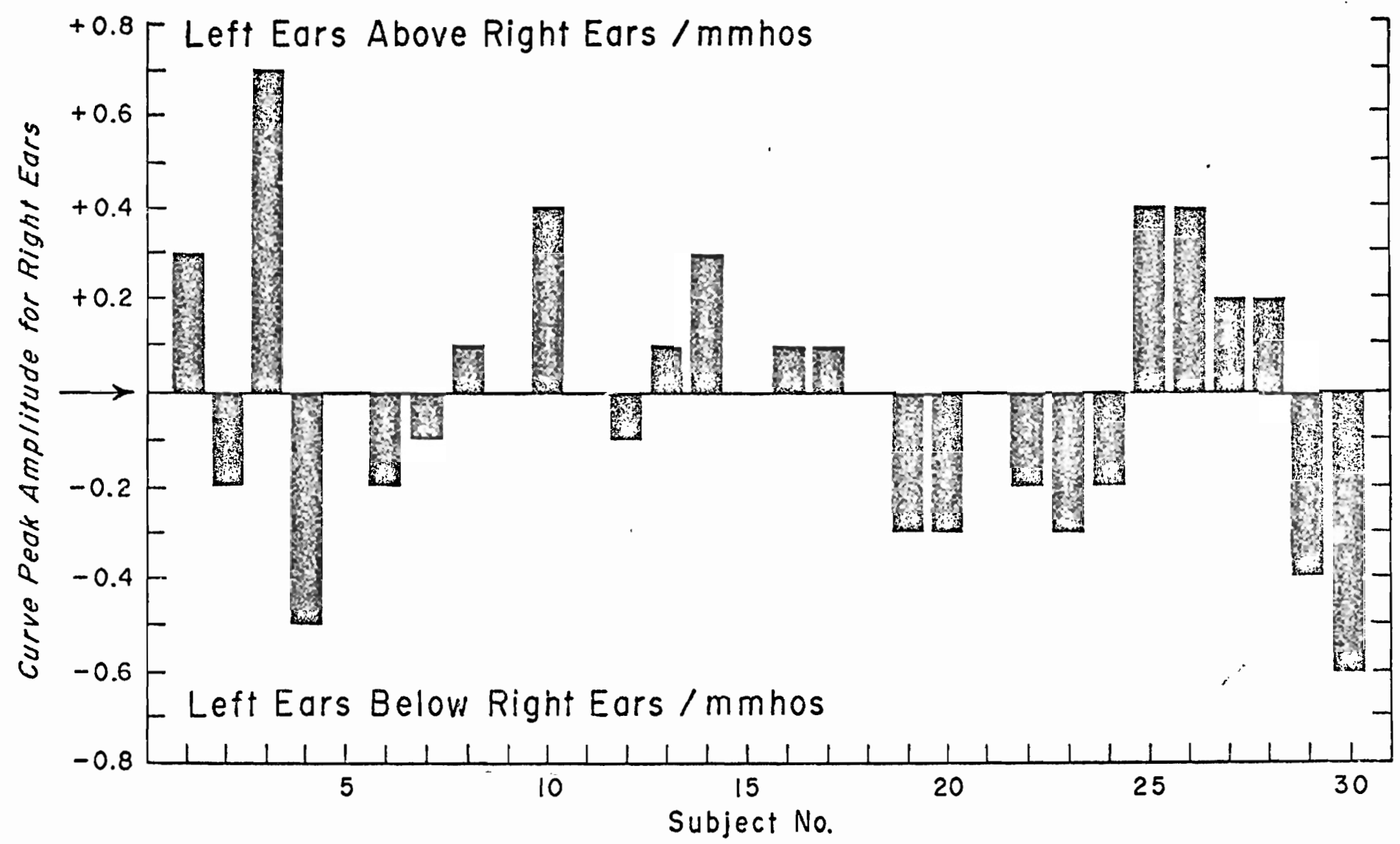

FIGURE 11. RELATIONSHIPS BETWEEN RIGHT AND LEFT EARS FOR MEASUREMENTS OF CURVE PEAK AMPLITUDE AT $660 \mathrm{~Hz}$. 
Curve Width

As illustrated by Figures 12 and 13 , there is a slight tendency for left ear measurements to differ in a positive direction from the baseline for right ear measurements of curve width at 220 and $660 \mathrm{~Hz}$. Figure 12 shows that between-ear differences range from 0 to $27 \mathrm{~mm} \mathrm{H}_{2} \mathrm{O}$ for measurements of curve width at 220 $\mathrm{Hz}$ with half of these differences being grouped between 0 and $9 \mathrm{~mm}$ $\mathrm{H}_{2} 0$. Between-ear differences range from 1 to $58 \mathrm{~mm} \mathrm{H}_{2} \mathrm{O}$ for measurements of curve width at $660 \mathrm{~Hz}$ according to Figure 13 and half of these differences are contained within a range of 1 to $17 \mathrm{~mm} \mathrm{H}_{2} \mathrm{O}$. Computed means for differences between right and left ear measurements of curve width were $11.23 \mathrm{~mm} \mathrm{H}_{2} \mathrm{O}$ at $220 \mathrm{H}_{\mathrm{z}}$ and $22 \mathrm{~mm} \mathrm{H}_{2} \mathrm{O}$ at $660 \mathrm{~Hz}$.

\section{Pressure at Curve Peak}

The relationships between right and left ear measurements of pressure at curve peak at 220 and $660 \mathrm{~Hz}$ (Figures 14 and 15) indicate that about an equal number of left ear measurements deviate in both a positive and negative direction from the baseline for right ear measurements. The magnitude of differences between right and left ear measurements of pressure at curve peak ranged from 2 to $43 \mathrm{~mm} \mathrm{H}_{2} \mathrm{O}$ at $220 \mathrm{~Hz}$ (Figure 14) and from 0 to $45 \mathrm{~mm} \mathrm{H}_{2} \mathrm{O}$ at $660 \mathrm{~Hz}$ (Figure 15). Figures 14 and 15 show that half of the between-ear differences range between 2 and $9 \mathrm{~mm} \mathrm{H}_{2} \mathrm{O}$ at $220 \mathrm{~Hz}$ and that two-thirds of the between-ear differences at 


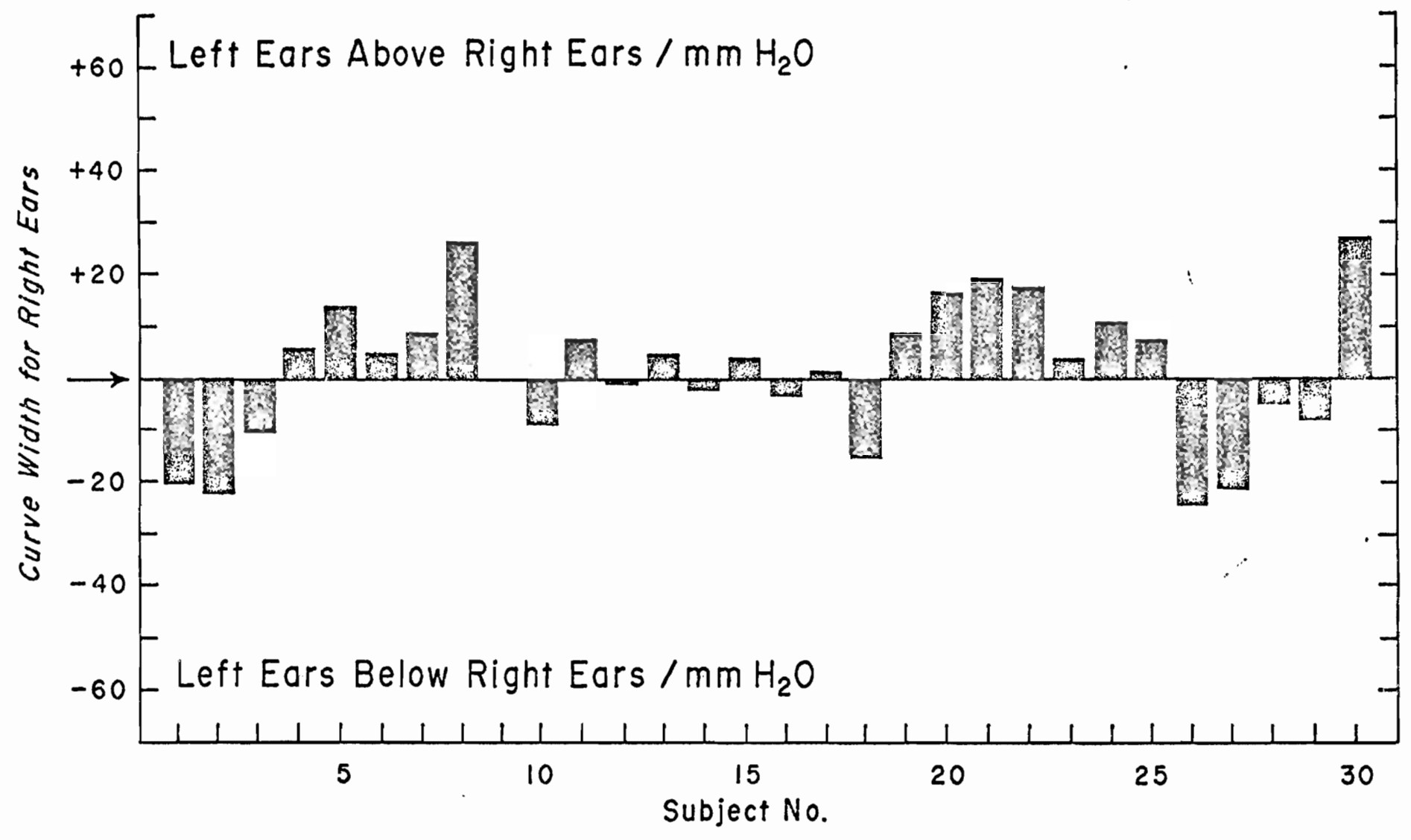

FIGURE 12. RELATIONSHIPS BETWEEN RIGHT AND LEFT EARS FOR MEASUREMENTS OF CURVE WIDTH AT $220 \mathrm{~Hz} . \underset{\infty}{-}$ 


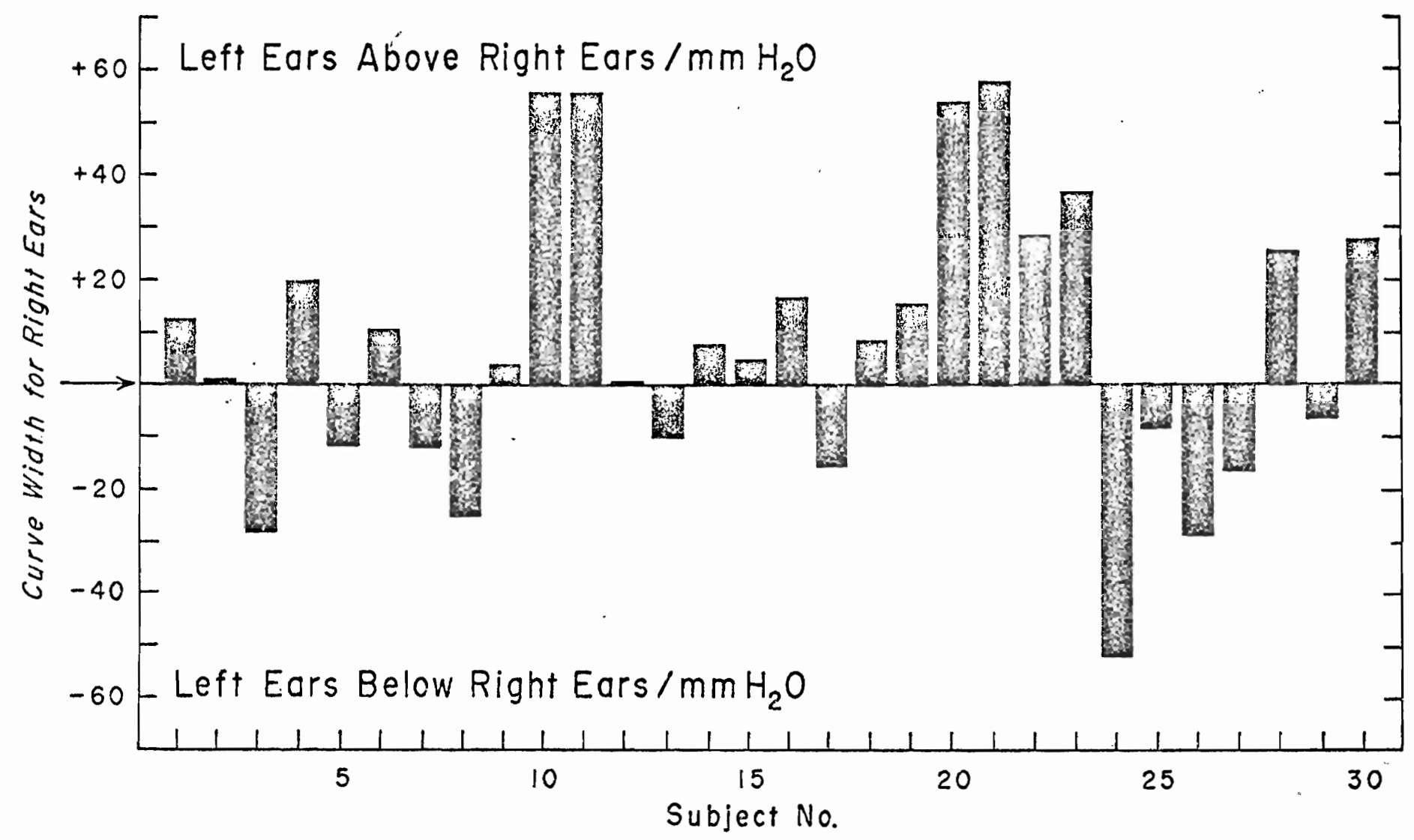

FIGURE 13. RELATIONSHIPS BETWEEN RIGHT AND LEFT EARS FOR MEASUREMEN TS OF CURVE WIDTH AT $660 \mathrm{~Hz}$. 


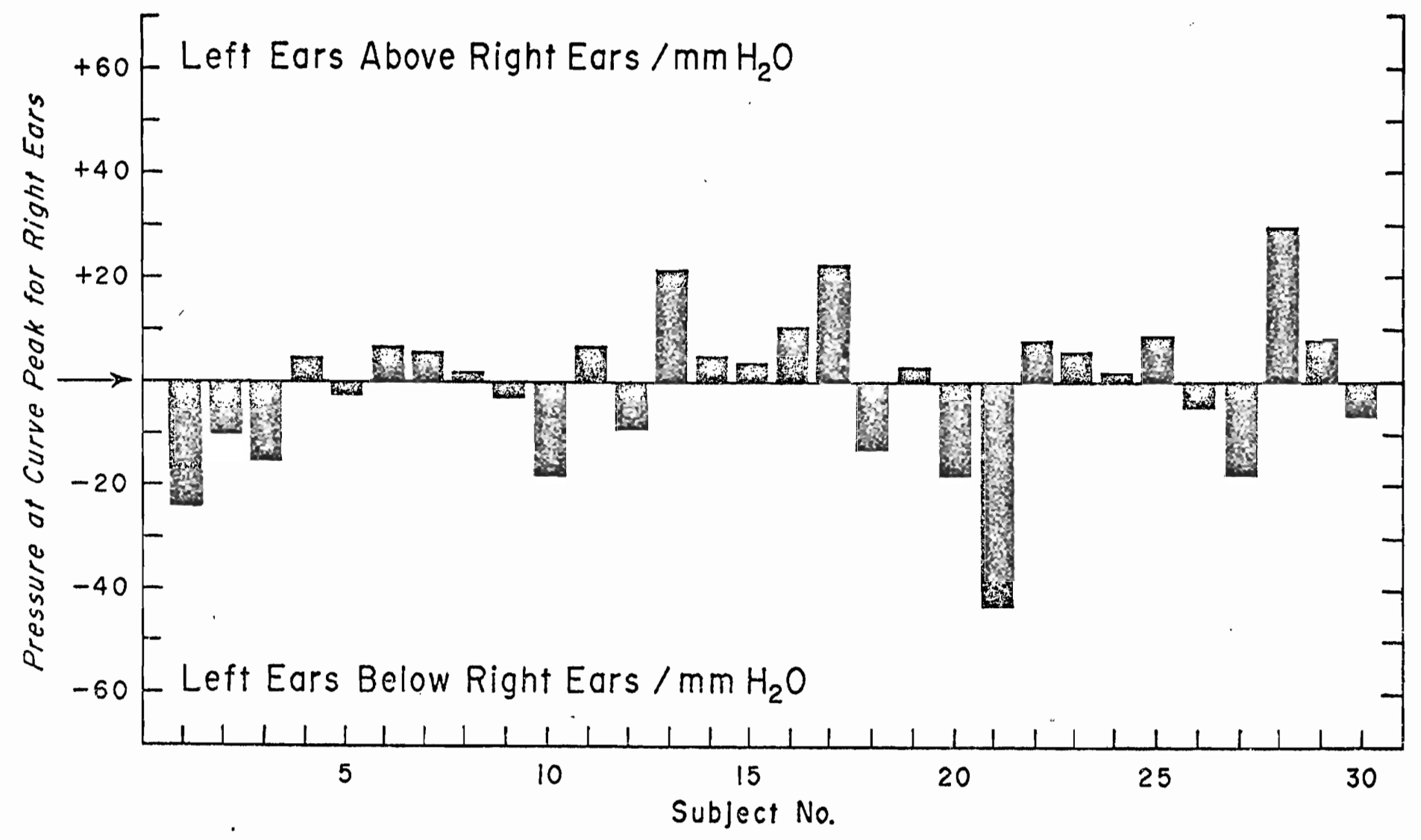

FIGURE 14. RELATIONSHIPS BETWEEN RIGHT AND LEFT EARS FOR MEASUREMEN TS OF PRESSURE AT CURVE PEAK AT $220 \mathrm{~Hz}$. 


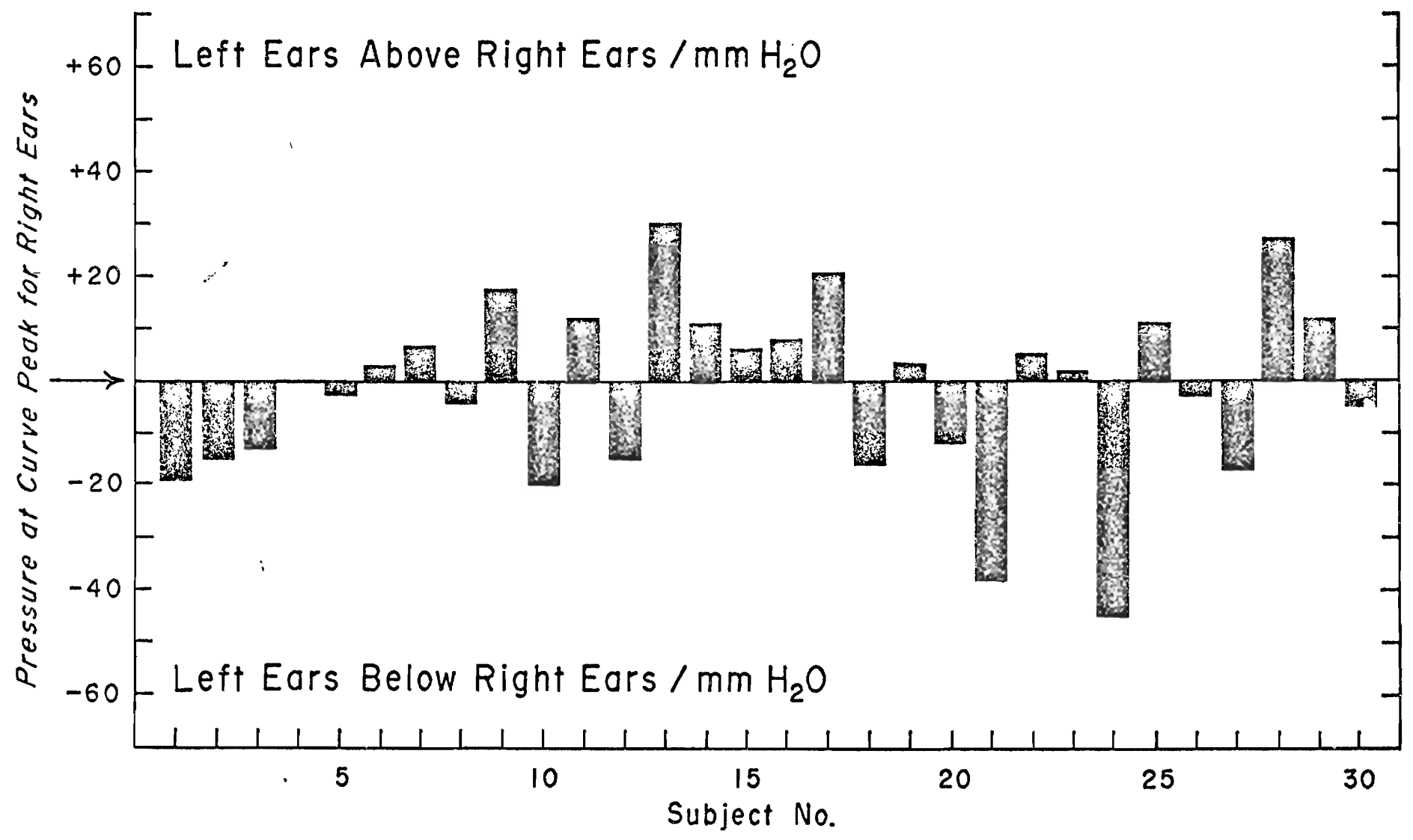

FIGURE 15. RELATIONSHIPS BETWEEN RIGHT AND LEFT EARS FOR MEASUREMENTS OF PRESSURE AT CURVE PEAKM AT $660 \mathrm{~Hz}$. 
$660 \mathrm{~Hz}$ are contained within a range of 0 to $15 \mathrm{~mm} \mathrm{H} \mathrm{H}_{2} \mathrm{O}$. Means for differences between right and left ear measurements of pressure at curve peak for all subjects were $11.43 \mathrm{~mm} \mathrm{H}_{2} \mathrm{O}$ at $220 \mathrm{~Hz}$ and $13.33 \mathrm{~mm} \mathrm{H} \mathrm{H}_{2} \mathrm{O}$ at $660 \mathrm{~Hz}$.

\section{v. RESULTS OF ADDITIONAL TESTING}

Five of the thirty subjects were retested within two weeks after their initial testing session. None of these subjects subjectively noticed any change in hearing sensitivity or experienced anything suggestive of middle ear pathology during the interim between initial testing and retest. The test procedure for retest was the same as that used in the original testing session. This was done as a check on the reliability of the measures obtained in the main study.

A comparison of initial and retest measures of curve peak anplitude for the same subject yielded differences that ranged from 0.0 to 0.1 mmhos at $220 \mathrm{~Hz}$ for right and left ears and from 0.0 to 0.2 mmhos for right ears and 0.0 to 0.1 mmos for left ears at $660 \mathrm{~Hz}$ for the five subjects tested. The mean of the differences for measures of curve peak amplitude for the two testing sessions was 0.02 mahos for right and left ears at $220 \mathrm{~Hz}$ and 0.10 mahos for right ears and 0.06 mmhus for left ears at $660 \mathrm{~Hz}$ (Appendix E, Tables IV and V).

Differences ranging from 0 to $22 \mathrm{~mm} \mathrm{H}_{2} \mathrm{O}$ for right ears and 1 to $13 \mathrm{~mm} \mathrm{H}_{2} \mathrm{O}$ for left ears at $220 \mathrm{~Hz}$ and from 2 to $25 \mathrm{~mm} \mathrm{H}_{2} \mathrm{O}$ for 
right ears and 0 to $9 \mathrm{rm} \mathrm{H}_{2} \mathrm{O}$ for left ears at $660 \mathrm{~Hz}$ were obtained between initial and retest measures of curve width for the five subjects tested. The means for these differences were $10.60 \mathrm{~mm}$ $\mathrm{H}_{2} \mathrm{O}$ for right ears and $6.40 \mathrm{~mm} \mathrm{H} \mathrm{H}_{2} \mathrm{O}$ for left ears at $220 \mathrm{~Hz}$ and $11.20 \mathrm{~mm} \mathrm{H}_{2} \mathrm{O}$ for right ears and $5.40 \mathrm{~mm} \mathrm{H}_{2} \mathrm{O}$ for left ears at $660 \mathrm{~Hz}$ (Appendix E, Tables IV and V).

Differences obtained between inftial and retest measures of pressure at curve peak for the five subjects tested ranged from 3 to $16 \mathrm{~mm} \mathrm{H}_{2} \mathrm{O}$ for right ears and 0 to $13 \mathrm{~mm} \mathrm{H}_{2} \mathrm{O}$ for left ears at $220 \mathrm{~Hz}$ and from 2 to $31 \mathrm{~mm} \mathrm{H}_{2} \mathrm{O}$ for right ears and 2 to $13 \mathrm{~mm}$ $\mathrm{H}_{2} \mathrm{O}$ for left ears at $660 \mathrm{~Hz}$. The means for these differences for measures of pressure at curve peak were $8.80 \mathrm{~mm} \mathrm{H}_{2} \mathrm{O}$ for right ears and $4.20 \mathrm{~mm} \mathrm{H}_{2} \mathrm{O}$ for left ears at $220 \mathrm{~Hz}$ and $15.00 \mathrm{~mm}$ $\mathrm{H}_{2} \mathrm{O}$ for right ears and $6.20 \mathrm{~mm} \mathrm{H}_{2} \mathrm{O}$ for left ears at $660 \mathrm{~Hz}$ (Appendix E, Tables IV and V).

\section{BETWEEN-SUBJECT MEASUREMENTS}

Table VII lists ranges, means, and standard deviations computed for tympanometry curve measurements on ail 60 normal ears under investigation. According to Table VII, measurements of curve peak amplitude for all ears range from 0.2 to 1.0 mnhos at $220 \mathrm{~Hz}$ and from 0.6 to 3.4 mmhos at $660 \mathrm{~Hz}$. Means for all measurements of curve peak amplitude are 0.48 mmhos at $220 \mathrm{~Hz}$ and 1.40 mmhos at $660 \mathrm{~Hz}$ with corresponding standard deviations of .17 and .72 mmhos. 


\section{BETWEEN-SUBJECT RANGES, MEANS, AND STANDARD DEVIATIONS FOR MEASUREMENTS OF CURVE PEAK AMPLITUDE, CURVE WIDTH, AND PRESSURE AT CURVE PEAK AT 220 AND $660 \mathrm{HZ}$}

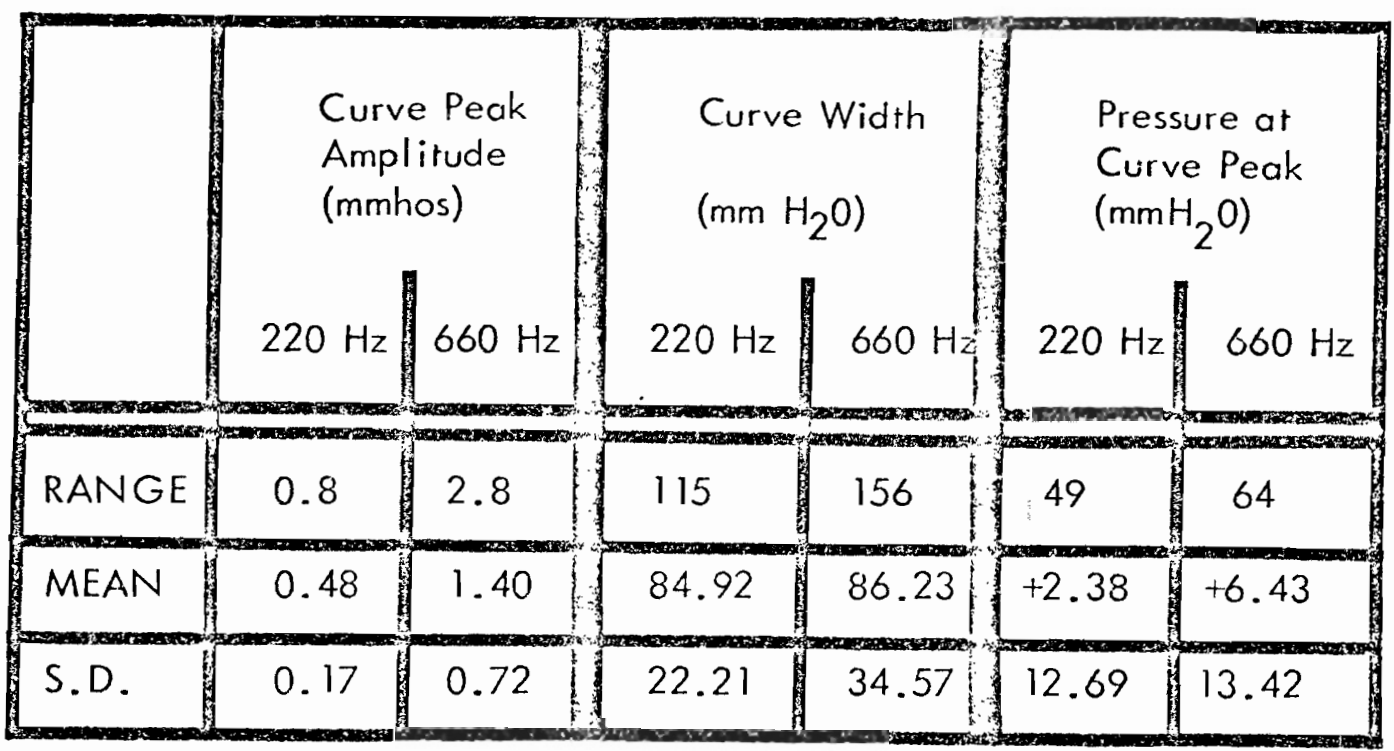


Measurements of curve width for all ears ranged from 31 to $146 \mathrm{~mm} \mathrm{H} \mathrm{H}_{2} \mathrm{O}$ at $220 \mathrm{~Hz}$ and from 24 to $180 \mathrm{~mm} \mathrm{H}_{2} \mathrm{O}$ at $660 \mathrm{~Hz}$ (Table VII). Means and standard deviations for all measurements of curve width as listed in Table VII are 84.92 and $22.21 \mathrm{~mm}$ $\mathrm{H}_{2} \mathrm{O}$ at $220 \mathrm{~Hz}$ and 86.23 and $34.57 \mathrm{~mm} \mathrm{H}_{2} \mathrm{O}$ at $660 \mathrm{~Hz}$.

As indicated by Table VII, all measurements of pressure at curve peak range from -21 to $+28 \mathrm{~mm} \mathrm{H} \mathrm{H}_{2} \mathrm{O}$ at $220 \mathrm{~Hz}$ and from -32 to $+32 \mathrm{mn} \mathrm{H} \mathrm{H}_{2} \mathrm{O}$ at $660 \mathrm{~Hz}$. Means for these measurements are $+2.38 \mathrm{~mm}$ $\mathrm{H}_{2} \mathrm{O}$ at $220 \mathrm{~Hz}$ and $+6.43 \mathrm{~mm} \mathrm{H} \mathrm{H}_{2} \mathrm{O}$ at $660 \mathrm{~Hz}$. Corresponding standard deviations are shown in Table VII to be 12.69 and $13.42 \mathrm{~mm} \mathrm{H}_{2} \mathrm{O}$. 
CHAPTER V

\section{DISCUSSION AND RECORMENDATIONS}

FOR FUTURE RESEARCH

The results of the Pearson Product-Moment Correlations between right and left ear tympanometry curve measurements show that, under the conditions of this study, significant correlations exist between right and left ear tympanometry curve measurements for the normal-hearing subjects utilized in this study. of the three tympanometry curve measurements investigated, only the between-ear correlation for tympanometry curve measurements of pressure at curve peak at $660 \mathrm{~Hz}$ did not demonstrate correlative significance.

According to the results of analysis of variance, the total measurement variability observed for the tympanometry curve measurements is predominantly due to differences between subjects with little or no measurement variability due to differences between each subject's right and left ears. Error of measurement contributed minimally to total measurement variability for measurements of curve peak amplitude and curve width, but accounted for a larger percentage of total measurement variability for measurements of pressure at curve peak. Although the percentage of total measurement variability due to between-subject differences and error of measurement was proportionately different for all 
tympanometry curve measurements, the percentage of total measurement variability attributed to between-ear differences was consistantly negligible.

Regression lines and confidence intervals for the right and left ear measurements of curve peak amplitude and curve width for each subject at 220 and $660 \mathrm{~Hz}$ (Figures 4, 5, 6 and 7) showed that most of these measurements were concentrated near the regression lines and that almost the entire number of these measurements could be confined within relatively narrow sets of boundaries. These observations are consistant with the obtained high correlations between right and left ear measurements of curve peak amplitude and curve width.

Individual right and left ear measurements of pressure at curve peak at 220 and $660 \mathrm{~Hz}$ were widely distributed around their respective regression lines (Figure 8 and 9). This would indicate that a lesser degree of interdependency exists between these individual right and left ear measurements within the established ranges for all pressure at curve peak measurements at 220 and $660 \mathrm{~Hz}$.

Between-subject data yielded results which show that measurements of curve peak amplitude at $660 \mathrm{~Hz}$ are larger than the same measurements at $220 \mathrm{~Hz}$ for all subjects in this study. While curve peak amplitude measurements are larger at $660 \mathrm{~Hz}$ than at. $220 \mathrm{~Hz}$, mean measurements of curve width are similar for both 
test frequencles. As such, curve width decreases relative to increases in curve peak amplitude. Means for all measurements of pressure at curve peak at 220 and $660 \mathrm{~Hz}$ indicate a minor positive deviation of the curve peak from $0 \mathrm{mrn} \mathrm{H}_{2} 0$. This deviation is slightly more for measurements at $660 \mathrm{~Hz}$. These findings agree with those of Liden, Peterson and Bjorkman (1970 b). Liden, Peterson and Bjorkman also suggest that a hysteresis effect of the impedance of the tympanic membrane to applied air pressure may be responsible for some of the observed shifts of the peak of the tympanometry curve. All deviations of pressure at curve peak observed for the subjects in the present study, however, fell within a range of plus and minus $32 \mathrm{mn} \mathrm{H}_{2} \mathrm{O}$ from $\mathrm{O} \mathrm{mm} \mathrm{H}_{2} \mathrm{O}$. The total sample produced tympanometry curve measurements which conform to what has been described as normal tympanometry curves (Liden, 1970 a and b; Jerger, 1970). An equal number of left ear tympanometry curve measurements differ in both positive and negative directions from right ear measurements. It also has been shown that the ranges of these between-ear differences are consistently greater for tympanometry curve measurements at $660 \mathrm{~Hz}$ than at $220 \mathrm{~Hz}$ (Figures 10, 11, 12, 13, 14 and 15). Al1 ranges of between-ear differences, especially for measurements of curve peak amplitude and curve width, however, are much reduced in comparison to the ranges of differences be-. tween subjects for the same measurements (Table VII). This 
illustrates that a much closer relationship exists between individual right and left ear tympanometry curve measurements than between the measurements for all subjects in this study. The results of repeat testing (Appendix E, Tables IV and v) show a high degree of consistency for measurements of curve peak amplitude with less test-retest consistency being observed for measurements of curve width and pressure at curve peak. Testretest comparisons also show that measurements of curve peak amplitude, curve width, and pressure at curve peak are generally not as consistent at $660 \mathrm{~Hz}$ as they are at $220 \mathrm{~Hz}$. This lesser degree of test-retest consistency for neasurements of curve peak amplitude at $660 \mathrm{~Hz}$ may be explained partially by the fact that millimho values are doubled for each division unit on the tympanogram for measurements at $660 \mathrm{~Hz}$ in comparison to values for measurements at $220 \mathrm{~Hz}$. Test-retest variations of the same magnitude would result in curve peak amplitude values at $660 \mathrm{~Hz}$ being twice as large as those at $220 \mathrm{~Hz}$. Reduced test-retest consistency for pressure at curve peak measurements at $660 \mathrm{~Hz}$ may be in part due to an increased influence of a hysteresis affect upon these measurements compared to the impact of such an affect upon the same measurements at $220 \mathrm{~Hz}$.

of the three tympanometry curve characteristics investigated, curve peak amplitude and curve width describe tympanometry curve configuratlons while pressure at curve peak locates tympanometry 
curves on the tympanogram relative to $0 \mathrm{~mm} \mathrm{H}_{2} 0$. As mentioned earlier the only major feature distinguishing tympanometry curves Indicative of ossicular chain discontinuity or otosclerosis from normal tympanometry curves is relatively different pojnts of maximum compliance (curve peak amplitude) on a compliance continuum. Although measurements of curve width have been shown to vary relative to increases and decreases in measurements of curve peak amplitude (Liden, Peterson and Bjorkman, $1970 \mathrm{~b}$ ), the measurement of curve peak amplitude is the single tympanometry curve characteristic which can best differentiate between a pathologically mobile or stiff middle ear and a normal middle ear (Jerger, 1970; Liden, Peterson and Bjorkman, $1970 \mathrm{a}$ and b; Lamb, 1971).

It has been suggested that due to individual anatomical symmetry, within-subject right and left ear tynpanometry curves for normal-hearing subjects should be in very close agreement in contrast to a range of normalcy based on between-subject measures. The results of this investigation have demonstrated that for practical purposes, no significant difference exists between right and left ear tympanometry curve measurements of curve pak amplitude and curve width, while a wide range of between-subject variation is shown for these same measurements under the conditions of this study. The close between-ear relationships for tympanometry curve measurements demonstrated by this study provide a basis for de- . veloping a more narrowly defined range of nornalcy. Such a 
definition of tympanometric normalcy would specify that not only must Individual right and left ear tympanometry curves fall within the range of normalcy established on between-subject tympanometry curve measurements, but also must not differ significantly. If some difference should exist between right and left ear measurements, it would be expected that this difference would be minimal and would not exceed the ranges established for normal betweenear differences. This definition of tympanometric normalcy should allow more precise clinical differentiation between normal and pathological middle ears than that standard provided by the present range of normalcy derived from between-subject tympanometry curve measurements. Should a difference between within-subject right and left ear tympanometry curves exceed the ranges established for normal between-ear differences, the clinician would be alerted to the possibility of middle ear pathology. Further clinical follow-up could then confirm the presence or absence of middle ear pathology, the side affected, and the type and degree of existing pathology.

Because of tts recent production, the Grason-Stadler Otoadmittance Meter has not been used extensively in clinical and research settings. As such, normative standards for measurements obtained with this instrument have not yet been established. Although the results of the present investigation provide normative tympanometric data for a snall number of subjects, additional research encompassing a larger population of normal-hearing 
Individuals must be conducted with the otoadmittance Neter before standards for tympanometric normalcy can be established for broad clinical application.

Normative tympanometric standards need to be established for various age groups. The middle ear undergoes a certain amount of anatomical and physiological change due to the aging process. This has been referred to as "conductive presbycusis" by Goodhill (1969). Such modifications of the middle ear system would suggest the necessity for further research designed to investigate possible between-subject and between-ear variations in tympanometry curve configurations due to age.

Another possible area of research could be directed towards the development of normative standards for between-subject and between-ear measurements of absolute inpedance. Such research utilizing the Otoadmittance Meter would need to be conducted on a large population of normal-hearing individuals in order to establish such standards for general clinical use.

Absolute admittance measurements in millinhos may be converted to values in acoustic ohms. This conversion would allow absolute admittance measurements for normal-hearing subjects obtained with the Otoadmittance Meter to be compared to absolute impedance measurements acquired with the Madsen Acoustic Impedance Meter. The results of such a comparison would be useful for interpreting similar clinical data generated from both the Otoadmittance Meter and the Madsen Acoustic Impedance Meter. 
A number of factors may be responsible for the percentage of total measurement variability due to error of measurement observed for the tympanometry curve measurements in this study. An investigation to determine these factors could provide information which would facilitate a better understanding of the variables inherent to the administration of tympanometry. 


\section{CHAPTER VI}

\section{SUMMARY AND CONCLUSIONS}

Tympanometry has been used for a number of years as a method for measuring middle ear function. Not only may tympanometry be used to distinguish between normal. and pathological middle ears, but it also provides a means of making differential diagnoses of middle ear pathology. Tympanometric standards based upon between-subject measures for normal-hearing individuals have been established in order to differentiate normal tympanometry curves from pathologjcal curves. These standards fail, however, to provide useful clinical norms for comparing withinsubject right and left ear tympanometry curves contained within the range of normalcy established for between-subject measures. During this study interest was directed to the investigation of differences beiween right and left ear tympanometry curves for normal-hearing individuals. The broad purpose of this investigation was to provide information regarding the within-subject relationship between tympanometry curves for right and left ears in a sample of normal-hearing subjects. This was done in an attempt to define a within-subject range of tympanometric normalcy. 
The question investigated by this study was as follows: Is there a difference between within-subject right and left ear tympanometry curves? To answer this question thirty normalhearing individuals, 18 to 30 years of age, were used as subjects. Both ears of each subject were tested individually. To balance the effects of ordering, the right ears of all evennumbered subjects and the left ears of all odd-numbered subjects were the first ears tested. For all subjects, however, tympanometry was administered first at $220 \mathrm{~Hz}$ and then at $660 \mathrm{~Hz}$ for each ear tested. All tympanometry testing was conducted utilizing a combined mode of conductance and susceptance. Three characteristics, curve peak amplitude, curve width, and pressure at curve peak, were measured and compared for each tympanometry curve.

An analysis of the cata obtained for the right and left ear tympanometry curve measurements led to the following conclusions :

1. Under the conditions of this investigation significant correlations were shown between right and left ear tympanometry curve measurements at both 220 and $660 \mathrm{~Hz}$ with the exception of pressure at curve peak measurements for $660 \mathrm{~Hz}$. The proximities of individual right and left ear tympanometry curve measurements to their respective regression lines were consistent with these correlations. 
2. Results of analysis of variance for the tympanometry curve measurements under investigation showed that total measurement variability was predominantly due to differences between subjects with only a slight amount of total measurement variability being attributed to differences between within-subject right and left ears.

3. Graphic representations of between-ear differences for all measurements under investigation illustrated that ranges of between-ear differences were much reduced in comparison to the computed ranges for between-subject measures. These representations also showed that approxinately an equal number of left ear measurements deviated in both positive and negative directions from the baseline for right ear measurements.

In conclusion, the results obtained under the conditions of this investigation demonstrated that for practical purposes no significant clinical difference exists between within-subject right and left ear tympanometry curves. These findings would suggest that a definition of tympanometric normalcy should be based not only upon between-subject measures, but also upon between-ear comparisons. Such a definition of tymanometric normalcy would specify that not only must within-subject right and left ear tympanometry curves fall within the range of normalcy established for 
between-subject measures, but also that these between-ear measures must not be significantly different. This definition would narrow the standard for tympanometric normalcy allowing precise differentiation between normal and pathological middle ears when comparing within-subject right and left ear tympanometry curves.

The outcome of this study clearly demonstrated that significant correlations exist between individual right and left ear tympanometry curve configurations at both test frequencies. Reasons for these correlations were discussed. Areas of possible future investigation also were suggested. 


\section{BIBLIOGRAPHY}

Alberti, P.W.R.M. and Kristensen, R., "The Clinical Application of Impedance Audiometry: A Prelininary Appraisal of an Electro-Acoustic Impedance Bridge." Laryngoscope, 80, 735-746 (1970).

Brooks, D.N., "An Objective Method of Determining Fluid in the Middle Ear." J. Int. Audiol., 7, 280 (1968).

Brooks, D.N., "The Use of the Electro-Acoustic Impedance Bridge in the Assessment of Middle Ear Function." J. Int. Audio1., 8, 563-569 (1969).

Bruning, J.L. and Kintz, B.L., Computation Handbook of Statistics. Illinois: Scott, Foresman and Company, 1968.

Feldman, A.S., "Acoustic Impedance Measurements as a Clinical Procedure." J. Int. Audiol., 3, 1-11 (1964).

Feldman, A.S., "Acoustic Impedance Studies of the Nornal Ear." J. Speech Hearing Res., 10, 165-i76 (1967).

Feldman, A.S., "Impadance Measurement and the Middle Ear, Part I." Maico Audiol. Lib. Series, 9, Rep. 7 (1971 a).

Feldman, A.S., "Impedance Measurement and the Middle Ear, Part II." Maico Audio1. Lib. Series, 9, Rep. 8 (1971 b).

Goodhill, V., "Bilateral Malleal Fixation and Conductive Presbycusis." Arch. Otolaryng., 90, $107-112$ (1969).

Jerger, J., "Clinical Experience with Impedance Audiometry." Arch. Otolaryng., 92, 311-324 (1970).

Klockhoff, I., "Clinical Use of Ear Impedance Measurements." J. Laryngol. Otol., 85, 243-254 (1971).

Lamb, L.E., "Impedance Measurement and the Middle Ear, Part III." Maico Audio1. Lib. Series, 9, Rep. 9 (1971).

Liden, G., Peterson, J.L. and Harford, E.R., "Simultaneous Recording of Changes in Relative Impedance and Air Pressure during Acoustic and Non-acoustic Elecitation of the MiddleEar Reflexes." Acta Otolaryng., Suppl. 263, 208-217 (1.970). 
Liden, G., Peterson, J.L. and Bjorkman, G., "Tympanometry: A Method for Analysis of Middle-Ear Function." Acta. Otolaryng., Supp.1. 263, 218-224 (1970 a).

Liden, G., Peterson, J.L. and Bjorkman, G., "Tympanometry." Arch. Otolaryng., 92, 248-257 (1970 b).

Lilly, D., "A Comparison of Acoustic Impedance Data Obtained with Madsen and Zwislocki Instruments." Paper presented to the American Speech and Hearing Association, 30 (1970).

Metz, 0., "The Acoustic Impedance Measured on Normal and Pathological Ears." Acta Otolaryng., Suppl. 63 (1946).

Moller, A.R., "Improved Technique for Detailed Measurement of the Middle Ear Impedance." J.Acoust. Soc. Amer., 32, 250-257 (1960).

Nilges, T.C., Northern, J.L. and Burke, K.S., "Zwislocki Acoustic Bridge: Clinical Correlations." Arch. Otolaryng., $89,69-86$ (1969).

O'Ne111, J.J. and Oyer, H.J., Applied Audiometry. New York: Dodd, Mead and Company, (1966).

Terkildsen, K. and Hielsen, S., "An Electro-Acoustic Impedance Measuring Bridise for Clinical Use." Arch. Otolaryng., $72,339-346$ (1960).

Zwislockt, J., "Some Impedance Measurements on Normal and Pathological Ears." J. Acoust. Soc. Amer., 29, 1312-1317 (1957).

Zwislocki, J., "Acoustic Measurement of the Middle Ear Function." Ann. Oto. Rhino. Laryng., 70, 599-606 (1961).

Zwislocki, J., "An Acoustic Method for Clinical Examination of the Ear." J. Speech Hearing Res., 6, 303-314 (1963). 
$\underline{A} \underline{P} \underline{P} \underline{E} \underline{N} \underline{D} \underline{I} \underline{X} \underline{E} \underline{S}$ 
APPENDIX A

\section{SUBJECT INSTRUCTIONS}


SUBJECT INSTRUCTIONS FOR TYMPANOMETRY TESTING

The following test is a method used for measuring middle ear function. You will hear two different test tones during the test administration. Please do not talk, remain quietly seated, and refrain as much as possible from making head movements and swallowing while testing is in process. Should you become uncomfortable during the testing procedure, please advise me of your discomfort so that I make whatever alterations are necessary. Are there any questions?

If you have any questions regarding the test results or how they relate to the measure of middle ear function, please feel free to ask those questions following test administration. 
APPENDIX B

INSTRUMENTATIOIN 


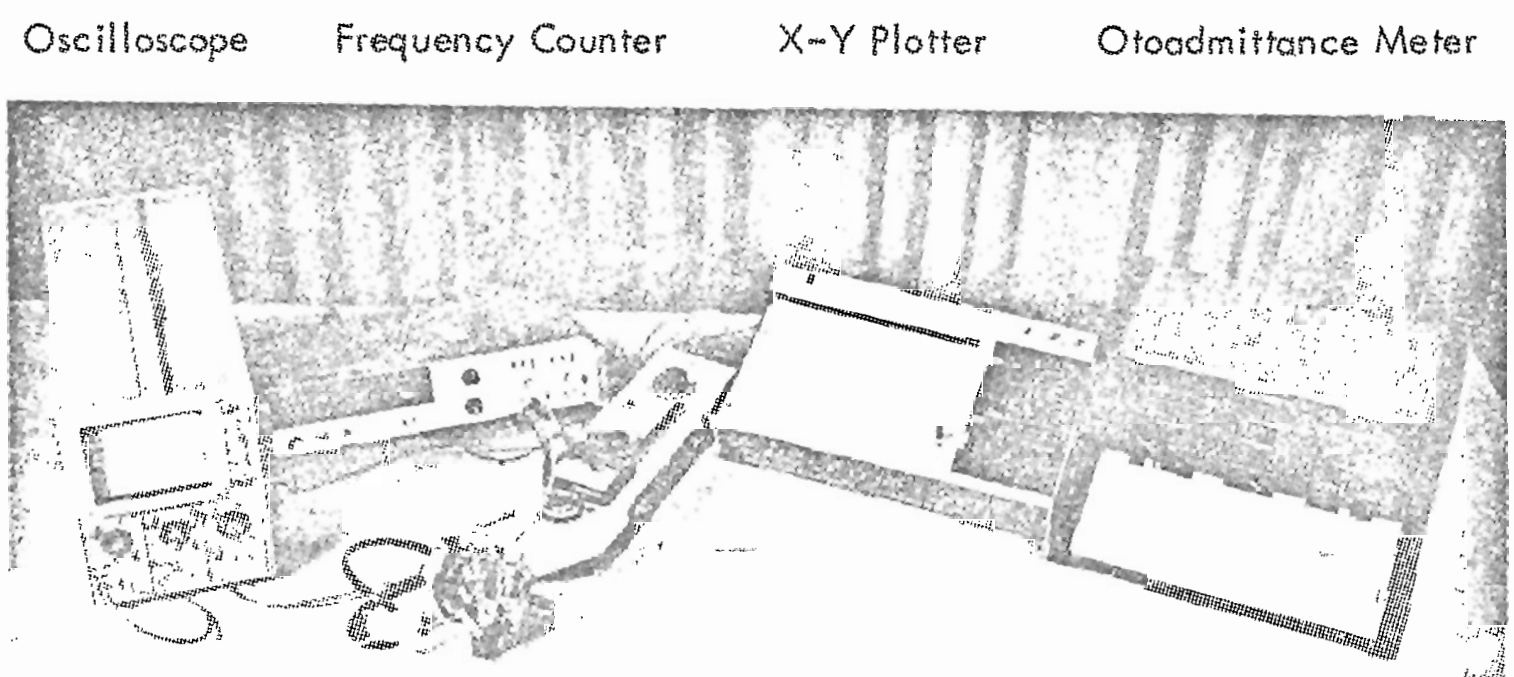

FIGURE 1. INSTRUMENTATION FOR TYMPANOMETRY TESTING. 


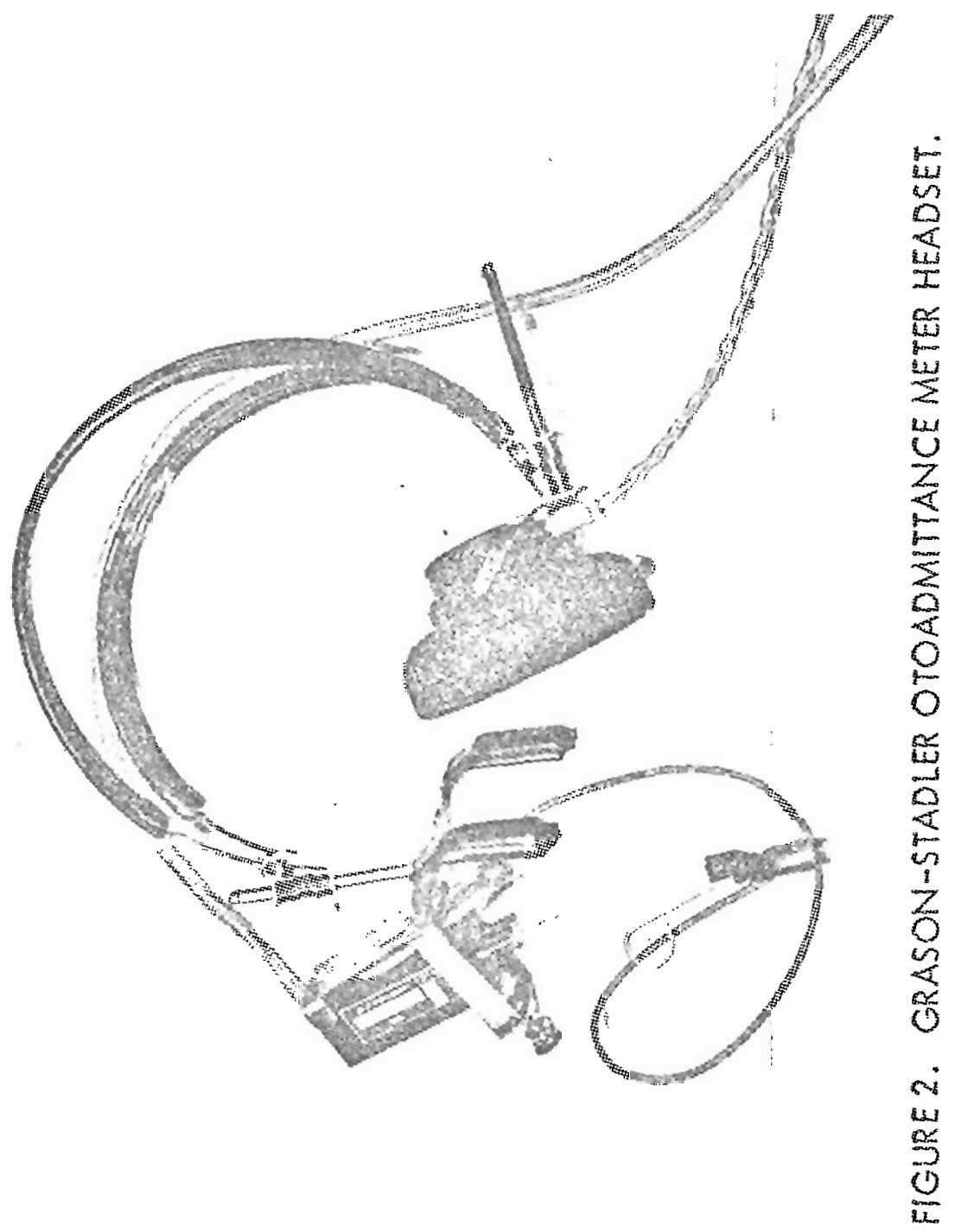




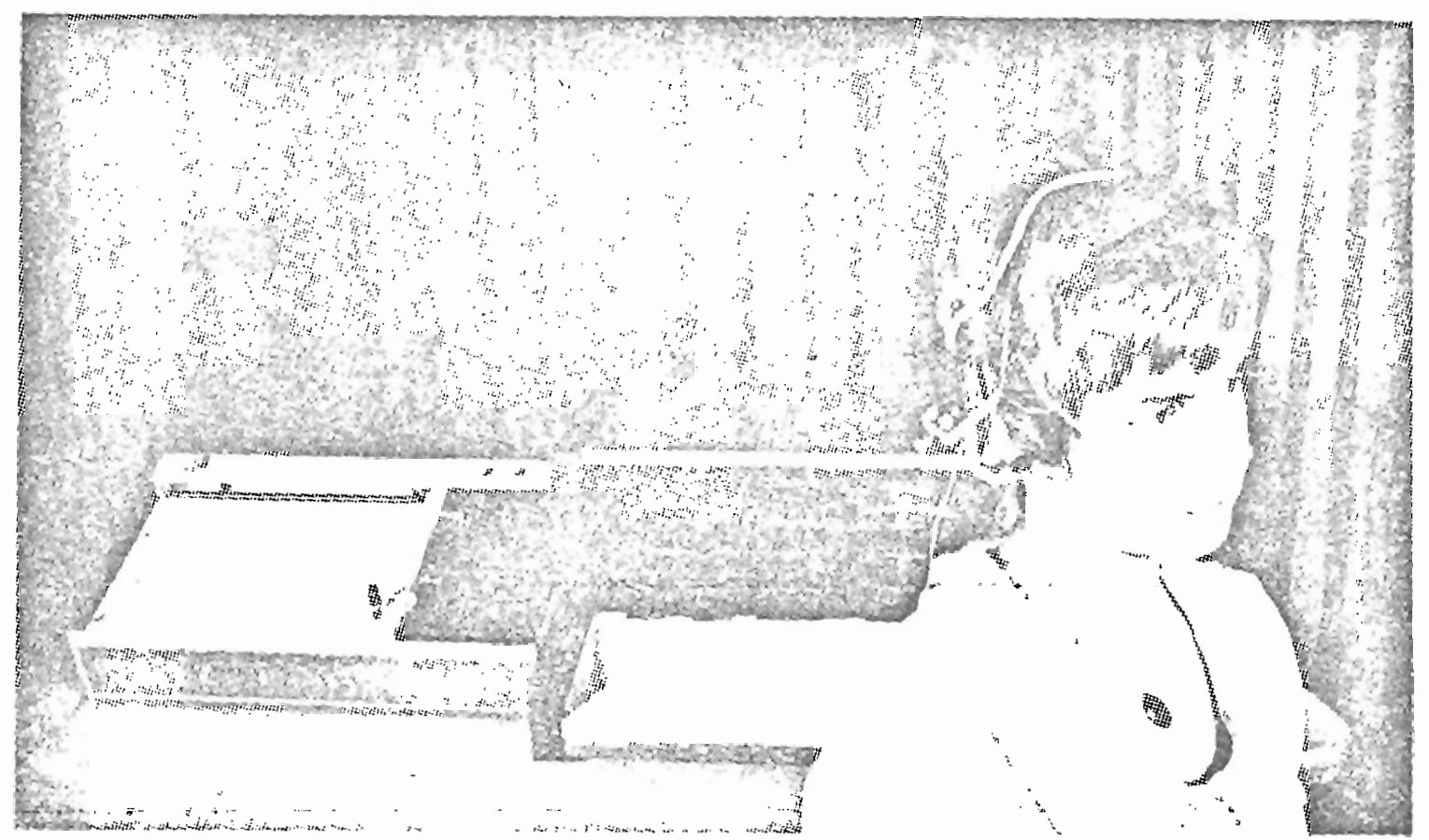

FIGURE 3. GRASON-STADLER OTOADMITIANCE METER HEADSET IN PLACE ON SUBJECT WITH EAR PROBE TIP INSERTED. 
APPENDIX C

TYMPANOGRAM 
SHOWN BELOW IS AN EXAMPLE OF SUBJECT TYMPANOMETRY CURVES ON A TYMPANOGRAM

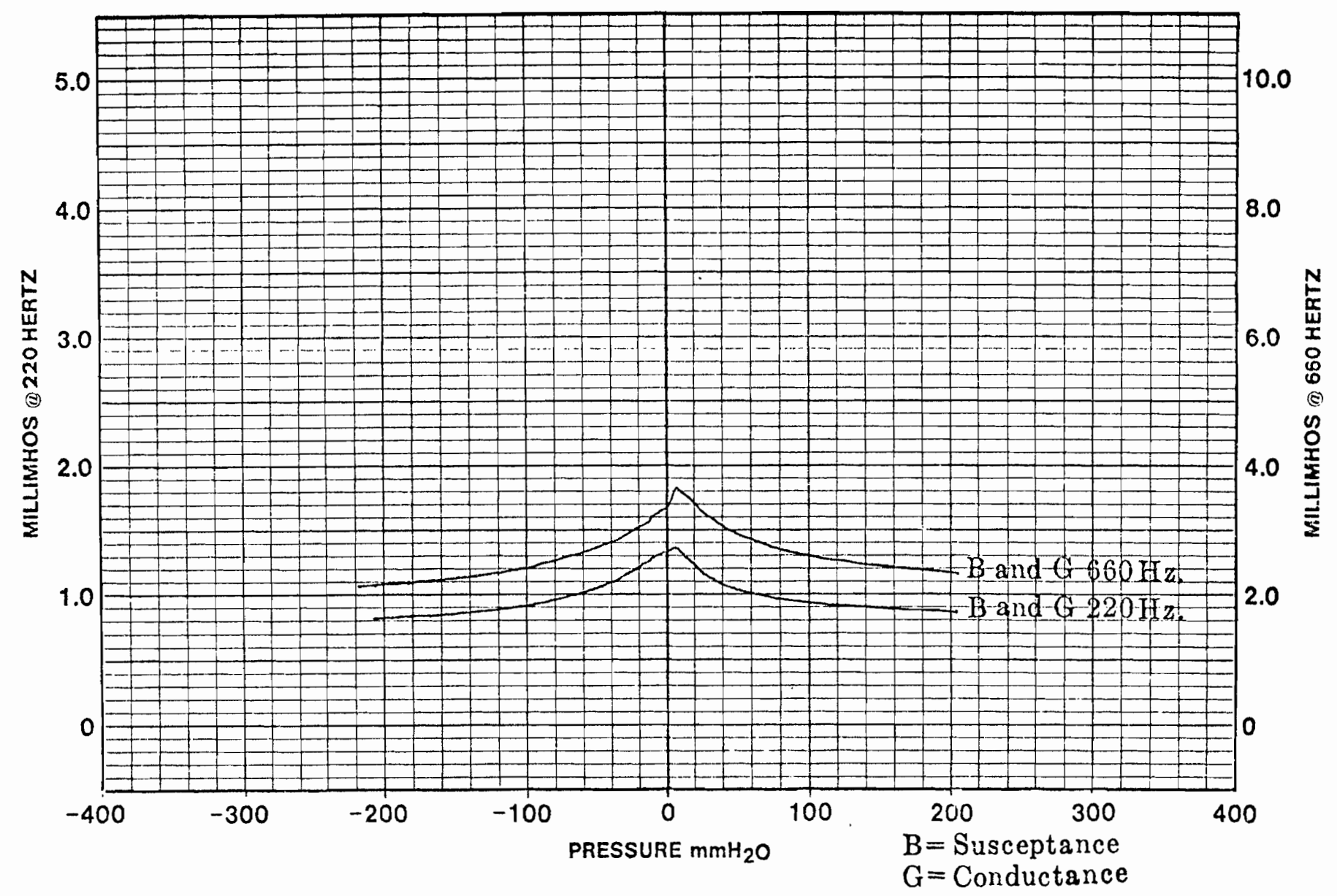




\section{APPENDIX D}

INDIVIDUAL TYMPANOMETRY CURVE MEASUREMENTS

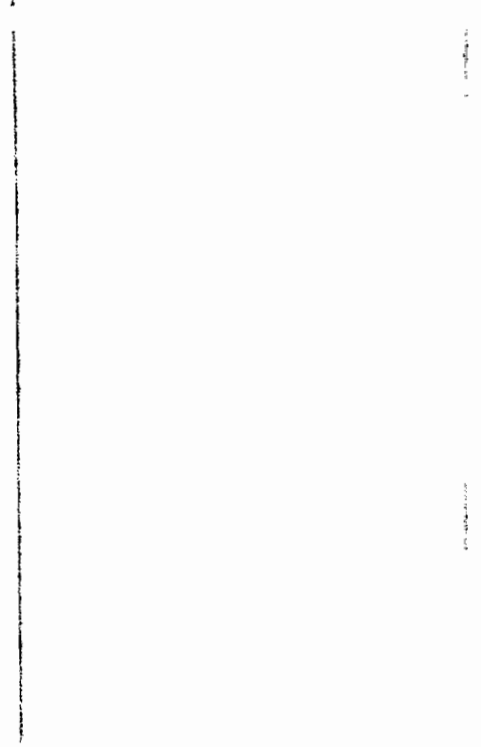


TABLE I

INDIVIDUAL MEASUREMENTS OF CURVE PEAK AMPLITUDE FOR RIGHT AND LEFT EARS

AT 220 AND $600 \mathrm{HZ}$

IN mmhos*

\begin{tabular}{|c|c|c|c|c|}
\hline \multirow{2}{*}{ 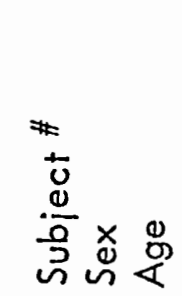 } & \multicolumn{2}{|c|}{$\begin{array}{l}\text { Curve Peak } \\
\text { Amplitude } \\
\text { At } 220 \mathrm{~Hz}\end{array}$} & \multicolumn{2}{|c|}{$\begin{array}{l}\text { Curve Peak } \\
\text { Amplitude } \\
\text { At } 660 \mathrm{~Hz}\end{array}$} \\
\hline & $R$ & L & $\mathrm{R}$ & $L$ \\
\hline $1-M-25$ & .8 & .8 & 2.1 & 2.4 \\
\hline $2-F-26$ & .5 & .4 & 1.1 & .9 \\
\hline $3-M-28$ & .4 & .6 & .9 & 1.6 \\
\hline $4-F-21$ & .5 & .4 & 1.8 & 1.3 \\
\hline $5-F-21$ & .5 & .5 & 1.2 & 1.2 \\
\hline $6-F-22$ & .3 & .3 & .8 & .6 \\
\hline $7-M-21$ & .6 & .6 & 2.1 & 2.0 \\
\hline $8-F-25$ & .4 & .5 & 1.5 & 1.6 \\
\hline $9-F-26$ & .3 & .3 & 1.2 & 1.2 \\
\hline $10-F-21$ & .4 & .4 & .8 & 1.2 \\
\hline $11-F-21$ & .6 & .5 & 1.0 & 1.0 \\
\hline $12-M-27$ & .7 & .5 & 1.5 & 1.4 \\
\hline $13-F-22$ & .2 & .3 & .7 & .8 \\
\hline $14-F-23$ & .5 & .4 & .9 & 1.2 \\
\hline $15-F-28$ & .7 & .7 & 2.5 & 2.5 \\
\hline $16-M-28$ & .4 & .4 & 1.3 & 1.4 \\
\hline $17-F-23$ & .4 & .5 & 1.3 & 1.4 \\
\hline $18-F-26$ & .3 & .3 & .8 & .8 \\
\hline $19-F-27$ & .4 & .4 & 1.1 & .8 \\
\hline $20-M-21$ & .7 & .6 & 2.3 & 2.0 \\
\hline $21-M-29$ & .5 & .6 & 1.7 & 1.7 \\
\hline $22-F-23$ & .3 & .2 & 1.0 & .8 \\
\hline $23-F-28$ & .4 & .4 & 1.1 & .8 \\
\hline $24-F-25$ & .3 & .2 & .8 & .6 \\
\hline $25-M-23$ & .4 & .4 & 1.0 & 1.4 \\
\hline $26-F-23$ & .3 & .4 & 1.0 & 1.4 \\
\hline $27-F-25$ & .4 & .4 & 1.0 & 1.2 \\
\hline $28-M-30$ & .9 & 1.0 & 3.2 & 3.4 \\
\hline $29-F-28$ & .7 & .6 & 2.9 & 2.5 \\
\hline $30-F-26$ & .8 & .7 & 2.5 & 1.9 \\
\hline
\end{tabular}

* All measurements obtained using a combined mode of conductance and susceptance. 
TABLE II

INDIVIDUAL MEASUREMENTS OF CURVE WIDTH

FOR RIGHT AND LEFT EARS

AT 220 AND $600 \mathrm{HZ}$

IN $\mathrm{mmH}_{2} \mathrm{O}$ *

\begin{tabular}{|c|c|c|c|c|}
\hline \multirow{2}{*}{ 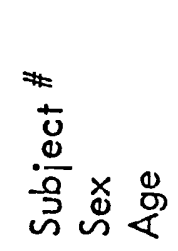 } & \multicolumn{2}{|c|}{$\begin{array}{l}\text { Curve Width } \\
\text { At } 220 \mathrm{~Hz}\end{array}$} & \multicolumn{2}{|c|}{$\begin{array}{l}\text { Curve Width } \\
\text { At } 660 \mathrm{~Hz}\end{array}$} \\
\hline & $R$ & $L$ & R & $L$ \\
\hline $1-M-25$ & 93 & 73 & 52 & 65 \\
\hline $2-F-26$ & 92 & 70 & 84 & 85 \\
\hline $3-M-28$ & 80 & 70 & 100 & 72 \\
\hline $4-F-21$ & 68 & 74 & 72 & 92 \\
\hline $5-F-21$ & 76 & 90 & 88 & 77 \\
\hline $6-F-22$ & 115 & 120 & 130 & 141 \\
\hline $7-M-21$ & 71 & 80 & 79 & 67 \\
\hline $8-F-25$ & 64 & 90 & 98 & 73 \\
\hline $9-F-26$ & 85 & 85 & 72 & 76 \\
\hline $10-F-21$ & 104 & 95 & 124 & 180 \\
\hline $11-F-21$ & 68 & 81 & 50 & 106 \\
\hline $12-M-27$ & 72 & 71 & 61 & 62 \\
\hline $13-F-22$ & 110 & 115 & 110 & 100 \\
\hline $14-F-22$ & 100 & 98 & 100 & 108 \\
\hline $15-F-28$ & 56 & 60 & 25 & 30 \\
\hline $16-M-28$ & 77 & 74 & 105 & 122 \\
\hline $17-F-23$ & 66 & 68 & 67 & 52 \\
\hline $18-F-26$ & 120 & 105 & 93 & 102 \\
\hline $19-F-27$ & 72 & 81 & 85 & 101 \\
\hline $20-M-21$ & 68 & 85 & 55 & 109 \\
\hline $21-M-29$ & 67 & 86 & 47 & 105 \\
\hline $22-F-23$ & 110 & 128 & 88 & 117 \\
\hline $23-F-28$ & 90 & 94 & 127 & 164 \\
\hline $24-F-25$ & 135 & 146 & 170 & 118 \\
\hline $25-M-23$ & 88 & is & 130 & 122 \\
\hline $26-F-23$ & 119 & 95 & 96 & 68 \\
\hline $27-F-25$ & 105 & 84 & 68 & 52 \\
\hline $28-M-30$ & 66 & 61 & 30 & 56 \\
\hline $29-F-28$ & $5 \mathrm{I}$ & 43 & 38 & 32 \\
\hline $30-F-26$ & 31 & 58 & 24 & 52 \\
\hline
\end{tabular}

* All measurements obtained using a combined mode of conductance and susceptance. 
INDIVIDUAL MEASUREMENTS OF PRESSURE AT CURVE PEAK FOR RIGHT AND LEFT EARS

AT 220 AND $660 \mathrm{HZ}$

IN $\mathrm{mmH}_{2} \mathrm{O}^{*}$

\begin{tabular}{|c|c|c|c|c|}
\hline \multirow{2}{*}{ 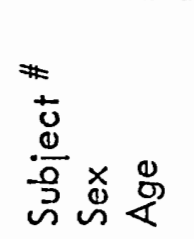 } & \multicolumn{2}{|c|}{$\begin{array}{l}\text { Pressure At } \\
\text { Curve Peak } \\
\text { At } 220 \mathrm{~Hz}\end{array}$} & \multicolumn{2}{|c|}{$\begin{array}{l}\text { Pressure At } \\
\text { Curve Peak } \\
\text { At } 660 \mathrm{~Hz}\end{array}$} \\
\hline & $\mathrm{R}$ & $L$ & $R$ & $L$ \\
\hline $1-M-25$ & +12 & -12 & +10 & -9 \\
\hline $2-F-26$ & +10 & 0 & +25 & +10 \\
\hline $3-M-28$ & +15 & 0 & +15 & +2 \\
\hline $4-F-21$ & -15 & -10 & -8 & -8 \\
\hline $5-F-21$ & +12 & +10 & +16 & +14 \\
\hline $6-F-22$ & -2 & +5 & +7 & +10 \\
\hline $7-M-21$ & +17 & +23 & +20 & +27 \\
\hline $8-F-25$ & 0 & +2 & +10 & +6 \\
\hline $9-F-26$ & +8 & +5 & -13 & +5 \\
\hline $10-F-21$ & +23 & +5 & +25 & +5 \\
\hline $11-F-21$ & +9 & +16 & +10 & +22 \\
\hline $12-M-27$ & +15 & +6 & +21 & +6 \\
\hline $13-F-22$ & -15 & +7 & -15 & +15 \\
\hline $14-F-23$ & -15 & -10 & -3 & +8 \\
\hline $15-F-28$ & +6 & +10 & +7 & +13 \\
\hline $16-M-28$ & 0 & +11 & +6 & +14 \\
\hline $17-F-23$ & -11 & +12 & -5 & +16 \\
\hline $18-F-26$ & -7 & -20 & 0 & -16 \\
\hline $19-F-27$ & -21 & -18 & -15 & -12 \\
\hline $20-M-21$ & +28 & +10 & +32 & +20 \\
\hline $21-M-29$ & +28 & -15 & +31 & -7 \\
\hline $22-F-23$ & 0 & +8 & +5 & +10 \\
\hline $23-F-28$ & +5 & +11 & +10 & +12 \\
\hline $24-F-25$ & -12 & -10 & +13 & -32 \\
\hline $25-M-23$ & +12 & +21 & +12 & +23 \\
\hline $26-F-23$ & -15 & -20 & -10 & -13 \\
\hline $27-F-25$ & +15 & -3 & +19 & +2 \\
\hline $28-M-30$ & -15 & +15 & -3 & +24 \\
\hline $29-F-28$ & -21 & -13 & -22 & -10 \\
\hline $30-F-26$ & +19 & +12 & +17 & +12 \\
\hline
\end{tabular}

* All measurements obtained using a combined mode of conductance and susceptance 
APPENDIX E

RESULTS OF ADDITIONAL TESTING 
TABLE IV

COMPARISON OF TEST RETEST RESULTS

AT $220 \mathrm{~Hz}$.

\begin{tabular}{|c|c|c|c|c|c|c|c|c|c|c|c|c|c|c|c|c|c|c|}
\hline \multirow[t]{3}{*}{$\begin{array}{c}\text { Subject } \\
\text { No. }\end{array}$} & \multicolumn{2}{|c|}{$\begin{array}{l}\text { Test Curve } \\
\text { Peak Ampl. } \\
\text { (mmhos) }\end{array}$} & \multicolumn{2}{|c|}{$\begin{array}{l}\text { Retest Curve } \\
\text { Peak Ampi. } \\
\text { (mmhos) }\end{array}$} & \multicolumn{2}{|c|}{$\begin{array}{l}\text { Difference } \\
\text { Between Test- } \\
\text { Retest Curve } \\
\text { Peok Ampl. } \\
\text { (mmhos) }\end{array}$} & \multicolumn{2}{|c|}{$\begin{array}{l}\text { Test Curve } \\
\text { Width } \\
\left(\mathrm{mmH}_{2} \mathrm{O}\right)\end{array}$} & \multicolumn{2}{|c|}{$\begin{array}{l}\text { Retest Curve } \\
\text { Width } \\
\left(\mathrm{mmH}_{2} \mathrm{O}\right)\end{array}$} & \multicolumn{2}{|c|}{$\begin{array}{l}\text { Diff. Between } \\
\text { Test-Retest Curve } \\
\text { Width }\left(\mathrm{mmH}_{2} \mathrm{O}\right)\end{array}$} & \multicolumn{2}{|c|}{$\begin{array}{l}\text { Test Press, at } \\
\text { Curve Peak Ampl. } \\
\left(\mathrm{mmH}_{2} \mathrm{O}\right)\end{array}$} & \multicolumn{2}{|c|}{$\begin{array}{l}\text { Retest Press. at } \\
\text { Curve Peak Ampl. } \\
\left(\mathrm{mmH}_{2} \mathrm{O}\right)\end{array}$} & \multicolumn{2}{|c|}{$\begin{array}{l}\text { Diff. Between } \\
\text { Test-Retest Press. a. } \\
\text { Curve Peak }\left(\mathrm{mmH}_{2} \mathrm{O}\right)\end{array}$} \\
\hline & \multicolumn{2}{|c|}{ EARS } & \multicolumn{2}{|c|}{ EARS } & \multicolumn{2}{|c|}{ EARS } & \multicolumn{2}{|c|}{ EARS } & \multicolumn{2}{|c|}{ EARS } & \multicolumn{2}{|c|}{ EARS } & \multicolumn{2}{|c|}{ EARS } & \multicolumn{2}{|c|}{ EARS } & \multicolumn{2}{|c|}{ EARS } \\
\hline & $R$ & L & $R$ & L & $R$ & L & $R$ & $L$ & $R$ & $L$ & $R$ & L & $\mathrm{R}$ & L & $R$ & L & $R$ & $\mathrm{~L}$ \\
\hline 3 & .4 & .6 & .4 & .6 & .0 & .0 & 80 & 70 & 80 & 65 & 0 & 5 & +15 & 0 & +25 & +13 & 10 & 13 \\
\hline 14 & .5 & .4 & .5 & .4 & .0 & .0 & 100 & 98 & 90 & 97 & 10 & 1 & -15 & -10 & -5 & -15 & 10 & 5 \\
\hline 18 & .3 & .3 & .3 & .3 & .0 & .0 & 120 & 105 & 100 & 92 & 20 & 13 & -7 & -20 & -10 & -20 & 3 & 0 \\
\hline 21 & .5 & .6 & .5 & .6 & .0 & .0 & 67 & 86 & 66 & 85 & 1 & 1 & +28 & -15 & +12 & -15 & 16 & 0 \\
\hline 27 & .4 & .4 & .3 & .3 & .1 & .1 & 105 & 84 & 83 & 72 & 22 & 12 & +12 & -3 & +7 & 0 & 5 & 3 \\
\hline & & & & Mean & 0.02 & 0.02 & & & & Mean & 10.60 & 6.40 & & & & $a n$ & 8.80 & 4.20 \\
\hline
\end{tabular}




\section{TABLE V}

COMPARISON OF TEST RETEST RESULTS

AT $660 \mathrm{~Hz}$.

\begin{tabular}{|c|c|c|c|c|c|c|c|c|c|c|c|c|c|c|c|c|c|c|}
\hline \multirow[t]{3}{*}{$\begin{array}{c}\text { Subject } \\
\text { No. }\end{array}$} & \multicolumn{2}{|c|}{$\begin{array}{l}\text { Test Curve } \\
\text { Peak Ampl. } \\
\text { (mmhos) }\end{array}$} & \multicolumn{2}{|c|}{$\begin{array}{l}\text { Retest Curve } \\
\text { Peak Ampl. } \\
\text { (mmhos) }\end{array}$} & \multicolumn{2}{|c|}{$\begin{array}{l}\text { Difference } \\
\text { Between Test- } \\
\text { Retest Curve } \\
\text { Peak Ampl. } \\
\text { (mmhos) }\end{array}$} & \multicolumn{2}{|c|}{$\begin{array}{l}\text { Test Curve } \\
\text { Width } \\
\left(\mathrm{mmH}_{2} \mathrm{O}\right)\end{array}$} & \multicolumn{2}{|c|}{$\begin{array}{l}\text { Retest Curve } \\
\text { Width } \\
\left(\mathrm{mmH}_{20} \mathrm{O}\right)\end{array}$} & \multicolumn{2}{|c|}{$\begin{array}{l}\text { Diff. Between } \\
\text { Test-Re test Curve } \\
\text { Width }\left(\mathrm{mmH}_{2} \mathrm{O}\right) \\
\text {. }\end{array}$} & \multicolumn{2}{|c|}{$\begin{array}{l}\text { Test Press, at } \\
\text { Curve Peak Ampl. } \\
\left(\mathrm{mmH}_{2} \mathrm{O}\right)\end{array}$} & \multicolumn{2}{|c|}{$\begin{array}{l}\text { Relest Press, at } \\
\text { Curve Peok Ampl. } \\
\left(\mathrm{mmH}_{2} \mathrm{O}\right)\end{array}$} & \multicolumn{2}{|c|}{$\begin{array}{l}\text { Diff. Between } \\
\text { Test-Retest Press. of } \\
\text { Curve Peak }\left(\mathrm{mmH}_{2} \mathrm{O}\right)\end{array}$} \\
\hline & \multirow{2}{*}{\multicolumn{2}{|c|}{ EARS }} & \multicolumn{2}{|c|}{ EARS } & \multicolumn{2}{|c|}{ EARS } & \multicolumn{2}{|c|}{ EARS } & \multicolumn{2}{|c|}{ EARS } & \multicolumn{2}{|l|}{ EARS } & \multicolumn{2}{|c|}{ EARS } & \multicolumn{2}{|c|}{ EARS } & \multicolumn{2}{|c|}{ EARS } \\
\hline & & & $R$ & L & $\mathrm{R}$ & L & $R$ & L & $\mathrm{R}$ & L & & L & $R$ & $L$ & $R$ & L & $R$ & $L$ \\
\hline 3 & .9 & 1.6 & 1.0 & 1.6 & .1 & .0 & 100 & 72 & 95 & 75 & 5 & 3 & +15 & +2 & +25 & +15 & 10 & 13 \\
\hline 14 & .9 & 1.2 & 1.1 & 1.1 & .2 & .1 & 150 & 108 & 125 & 117 & 25 & 9 & -3 & +8 & +5 & +10 & 8 & 2 \\
\hline 18 & .8 & .8 & .9 & .8 & .1 & .0 & 93 & 102 & 108 & 95 & 15 & 7 & 0 & -16 & -2 & -20 & 2 & 4 \\
\hline 21 & 1.7 & 1.7 & 1.8 & 1.6 & .1 & .1 & 47 & 105 & 56 & 105 & 9 & 0 & +31 & -7 & 0 & -11 & 31 & 4 \\
\hline 27 & 1.0 & 1.2 & 1.0 & 1.1 & .0 & .1 & 68 & 52 & 70 & 60 & 2 & 8 & +19 & +2 & -5 & -6 & 24 & 8 \\
\hline & & & & & .10 & .06 & & & & lean & 11.20 & 5.40 & & & & ean & 15.00 & 6.20 \\
\hline
\end{tabular}

